OAK RIDGE

NATIONAL

LABORATORY

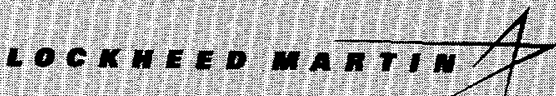
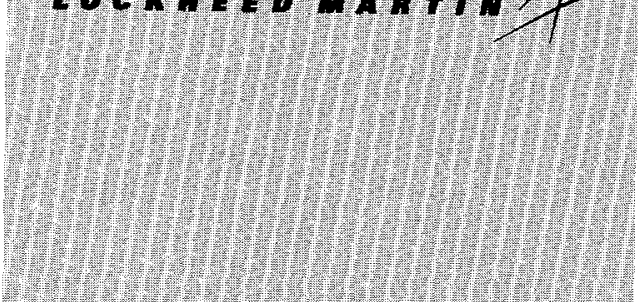

Hitis
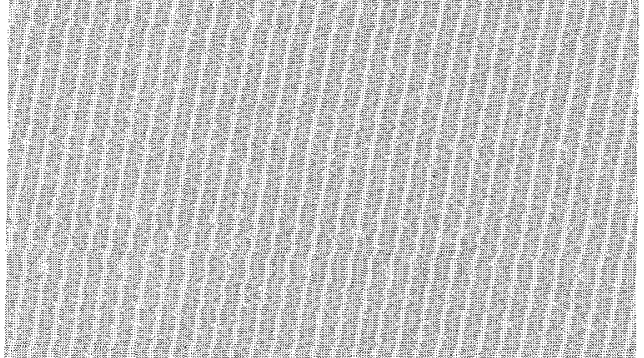

(1.).

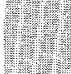

(1)

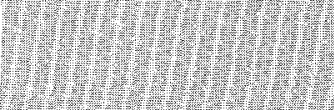

(i)

तitis

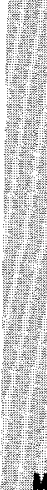

VANAGEO ANO OPERATEO BY

LOCKHEED WARTW ENERGY RESEAROH CORPORATION FOR THE UNTED STATES DEPARTUENT OF ENERGY

ORNL-27 (3-96)

$$
\begin{aligned}
& \text { RECEIVEO } \\
& \text { SUL O } 21099 \\
& \text { OSTI }
\end{aligned}
$$

\section{Development of the ENDF/B-VI Atom Displacement Cross Sections for Iron}

\author{
I. Remec \\ J. E. White
}


Contract Program or Title:

Subject of this Document:

Type of Document:

Author:

Date of Document:

Responsible NRC Individual and NRC Office or Division:
Embrittlement Data Base and Dosimetry Evaluation Program

Development of the ENDF/B-VI Atom Displacement Cross Sections for Iron

Letter Report

I. Remec, J. E. White

June 1999

C. Fairbanks (301-415-6014)

Division of Engineering, U.S. Nuclear

Regulatory Commission

Prepared for the

U.S. Nuclear Regulatory Commission

Washington, DC 20555

under Interagency Agreement DOE 1886-N616-4W

NRC JCN No. W6164

OAK RIDGE NATIONAL LABORATORY

Oak Ridge, TN 37831-6363

managed by

LOCKHEED MARTIN ENERGY RESEARCH CORP.

for the

U.S. Department of Energy

under contract DE-AC05-96OR22464. 
ORNL/NRC/LTR-99/4

Development of the ENDF/B-VI Atom Displacement Cross Sections for Iron

\author{
I. Remec \\ J. E. White
}

Manuscript Completed - May 1999

Date Published - June 1999

\author{
Prepared for the \\ U.S. Nuclear Regulatory Commission \\ Washington, DC 20555 \\ under Interagency Agreement DOE 1886-N616-4W
}

NRC JCN No. W6164

Prepared by the

OAK RIDGE NATIONAL LABORATORY

Oak Ridge, TN 37831-6363

managed by

LOCKHEED MARTIN ENERGY RESEARCH CORP.

for the

U.S. Department of Energy

under contract DE-AC05-96OR22464 


\section{DISCLAIMER}

This report was prepared as an account of work sponsored by an agency of the United States Government. Neither the United States Government nor any agency thereof, nor any of their employees, make any warranty, express or implied, or assumes any legal liability or responsibility for the accuracy, completeness, or usefulness of any information, apparatus, product, or process disclosed, or represents that its use would not infringe privately owned rights. Reference herein to any specific commercial product, process, or service by trade name, trademark, manufacturer, or otherwise does not necessarily constitute or imply its endorsement, recommendation, or favoring by the United States Government or any agency thereof. The views and opinions of authors expressed herein do not necessarily state or reflect those of the United States Government or any agency thereof. 


\section{DISCLAIMER}

Portions of this document may be illegible in electronic image products. Images are produced from the best available original document. 


\begin{abstract}
The atom displacement (dpa) cross sections for iron given in the ASTM Standard Practice E 693 are based on the data from ENDF/B-IV. Since ENDF/B-IV the cross sections have been changed considerably. In particular for iron, ENDF/B-VI gives cross-section evaluations for the individual isotopes with more forward-directed inelastic scattering, and reduced magnitude of the inelastic scattering at high energies.

This report provides the displacement cross sections for iron generated from the ENDF/B-VI data and documents the procedure used to calculate the new dpa cross sections.

Over most of the energy range the new ENDF/B-VI dpa cross sections agree with the ENDF/B-IV dpa cross sections to within 10\%; however, differences of up to $60 \%$ are present in the energy region around $10 \mathrm{keV}$. The corresponding differences in the integral dpa rates (integral over the neutron spectrum) were found to be within $5 \%$ for the case of the pressurized water reactor considered (H. B. Robinson-2). The ENDF/B-VI displacement cross sections resulted in slightly lower dpa rates in the softer neutron spectrum close to the pressure vessel inner wall and up to $\sim 4 \%$ higher dpa rates in the region close to the pressure vessel outer surface. Similar changes in dpa rates are expected to be found in other pressurized water reactors: smaller differences will likely be found in thinner pressure vessels and larger differences in thicker pressure vessels.

The changes in the dpa rates caused by the new ENDF/B-VI displacement cross sections are relatively small and are, consequently, not expected to introduce a bias in embrittlement data bases if new results - based on ENDF/B-VI dpa - are added to the existing data, based on ENDF/B-IV dpa cross sections. On the other hand, updating the iron-displacement cross sections to ENDF/B-VI is desirable, because it will establish consistency between the cross sections used for the neutron transport calculations and the cross sections used to calculate the dpa. It appears appropriate, therefore, to recommend an update of the ASTM standard E 693 with the ENDF/B-VI displacement cross sections reported in this work.
\end{abstract}




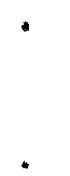




\section{CONTENTS}

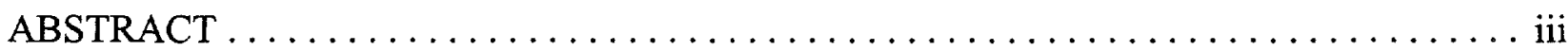

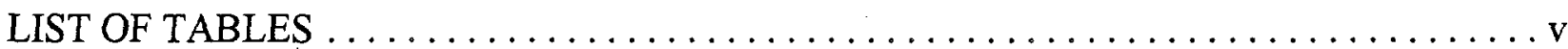

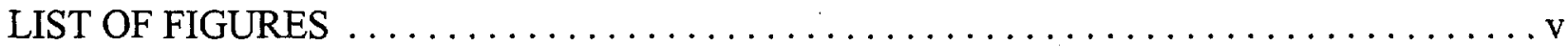

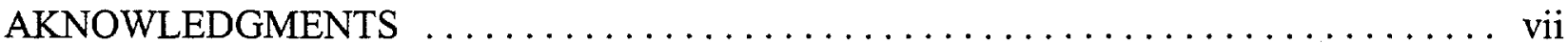

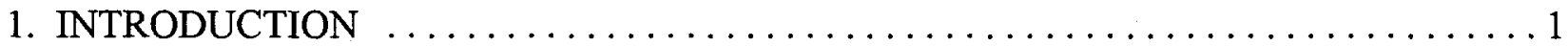

2. GENERATION OF THE IRON-DISPLACEMENT CROSS SECTIONS FROM

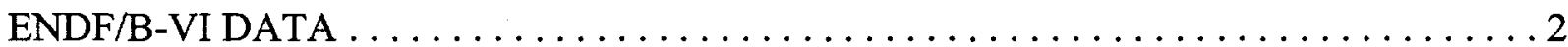

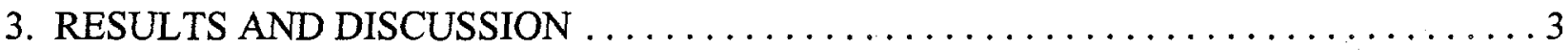

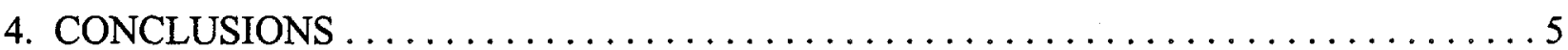

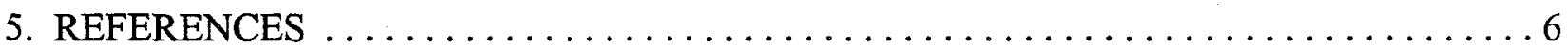

\section{TABLES}

Table 1 Reactions processed in the calculation of the damage energy cross sections

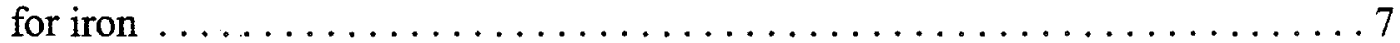

Table 2 Comparison of the dpa rates calculated with the ENDF/B-IV and ENDF/B-VI displacement cross sections for iron. The dpa rates are given versus distance from the

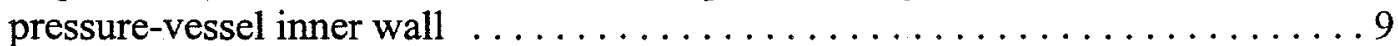

Table 3 Displacement cross sectios for iron derived from ENDF/B-VI data $\ldots \ldots \ldots 10$

\section{FIGURES}

Figure 1 An illustration of the effect of changing the cutoff energy $E_{R}$ in HEATR from 25 to $40 \mathrm{eV}$ on the iron displacement cross sections. The displacement cross sections from

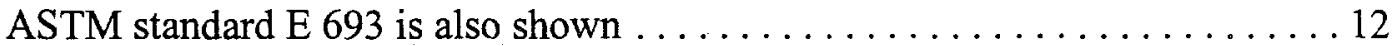

Figure 2 Details of the energy region in which the change of the $E_{R}$ results in the largest change in the displacement cross sections $\ldots \ldots \ldots \ldots \ldots \ldots \ldots \ldots \ldots \ldots$

Figure 3 Comparison of the displacement cross sections for $\mathrm{Fe}-56$ for the infinitely diluted material and for different background cross sections $\sigma_{0} \ldots \ldots \ldots \ldots \ldots 14$ 
Figure 4 Contributions of the iron isotopes to the displacement cross sections of natural iron .................................... 15

Figure 5 Relative contributions (in percent) of the individual iron isotopes to the displacement

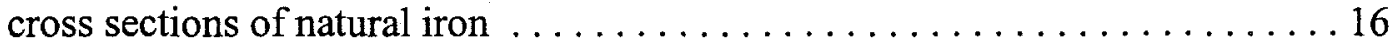

Figure 6 Relative contributions (in percent) of different types of neutron reactions to the total dpa cross section for Fe-56 ........................ 17

Figure 7 Comparison of the "new" ENDF/B-VI iron-displacement cross sections and the irondisplacement cross sections from ASTM standard E $693 \ldots \ldots \ldots \ldots \ldots 18$

Figure 8 Differences (in percent) between the "new" (ENDF/B-VI) and "old" iron-

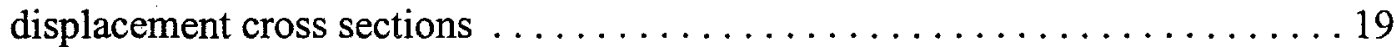




\section{ACKNOWLEDGMENTS}

The authors wish to express their appreciation to the reviewers, N. M. Greene and J. V. Pace III of the Oak Ridge National Laboratory. Special thanks go to C. H. Shappert for providing the editorial review and to $M$. R. Whittenbarger for the preparation of this report. The work was performed as a part of the "Embrittlement Data Base and Dosimetry Evaluation Program" (FIN W6164) sponsored by the Nuclear Regulatory Commission and managed by Carolyn Fairbanks of the Nuclear Regulatory Commission. 


\section{INTRODUCTION}

In the studies of the steel property changes caused by neutron irradiation the neutron exposure is most often characterized by the fast neutron fluence. The fast fluence usually refers to the fluence of neutrons with energies above $1.0 \mathrm{MeV}$, or less often to the fluence of neutrons with energies above $0.5 \mathrm{MeV}$ or $0.1 \mathrm{MeV}$. These exposure indexes are relatively easy to determine; however, they do not assess the energy distribution of the neutrons above the threshold, and do not account for the interaction of neutrons with the material. To overcome these shortcomings and to make the neutron exposure index more representative of the dominant physical source of neutron radiation damage in metals, which is the displacement of atoms from their normal lattice sites, the exposure index "displacements per atom" (dpa) was introduced some 30 years ago (Refs. 1-3). The dpa is the number of times, on the average, that an atom has been displaced during irradiation. Dpa has become a generally accepted exposure index for characterizing the neutron irradiations of iron and low-alloy steels. The displacement cross sections for iron and the standard procedure for calculating the dpa are given in the ASTM Standard Practice E 693 (Ref. 4).

In the current methodology for the determination of the radiation embrittlement of reactor vessel materials, as described in the U.S. Nuclear Regulatory Commission Regulatory Guide 1.99, Rev. 2 (Ref. 5), the calculated dpa is used as an alternative method for determining the fast-fluence attenuation in the pressure vessel (PV) wall.

The dpa cross sections given in the ASTM Standard Practice E 693 (Ref. 4) are based on the data from ENDF/B-IV (Ref. 4). Since ENDF/B-IV, the iron cross-section evaluations have changed considerably. In particular, for iron, ENDF/B-VI gives cross sections for the individual isotopes, more forward-directed inelastic scattering, and reduced magnitude of the inelastic scattering at high energies. These changes have made a significant impact on neutron transport calculations: the ENDF/B-VI cross sections result in a reduced attenuation of the fast fluxes through the reactor PV walls and higher fast neutron fluxes in the reactor cavities. In general the ENDF/B-VI cross sections produce better agreement of the calculated and measured dosimetry reaction rates and remove the decrease of the calculated-to-measured reaction rate ratios with the increasing thickness of steel penetrated, which was typical for calculations with the pre-ENDF/B-VI cross sections.

Because of the considerable changes in the iron cross sections it is necessary to evaluate the impact on the dpa cross sections. The scope of the work presented here is to generate the dpa cross sections for iron from the ENDF/B-VI data and present comparisons with the ASTM dpa cross sections. 


\section{GENERATION OF THE IRON-DISPLACEMENT CROSS SECTIONS FROM ENDF/B-VI DATA}

The new iron dpa cross sections were obtained by processing the ENDF/B-VI iron data with the NJOY (Ref. 6) code. The NJOY (version 94.105) module HEATR was used to calculate the damage energy production cross sections. The isotopes processed were $\mathrm{Fe}^{54}(\mathrm{MAT}=2625, \mathrm{MOD} 1), \mathrm{Fe}^{56}$ $(\mathrm{MAT}=2631, \mathrm{MOD} 1), \mathrm{Fe}^{57}(\mathrm{MAT}=2634, \mathrm{MOD} 1)$, and $\mathrm{Fe}^{58}(\mathrm{MAT}=2637, \mathrm{MOD} 1)$.

When a neutron interacts with an atom in the lattice, the atom receives some kinetic energy. If the kinetic energy of the primary knock-on atom (PKA) is greater than the displacement threshold energy, $E_{d}$, the atom is displaced from its lattice site. Often the PKA has kinetic energy high enough that it can displace other atoms before stopping in the lattice. A part of the PKA energy is lost in electron excitations, the rest of the PKA's energy - the so-called damage energy - is used to displace atoms. The interaction of an energetic neutron, therefore, results in a cascade of displaced atoms. The fraction of the PKA energy available to cause displacements was calculated by Linhard (Ref. 7). In HEATR the Robinson formulation of the Linhard energy partition function is used (Ref. 8). In the calculation of the damage energy cross sections, the Robinson partition function is set to zero below the threshold energy $E_{R}$.

Different reactions contribute to the damage energy and need to be taken into account. NJOY processes all the reactions present on the ENDF/B tape. A complete list of the reactions processed for each of the iron isotopes is given in Table 1. Besides the total damage energy cross section, HEATR calculates partial damage energy cross sections due to elastic scattering (contribution from reaction $M T=2$ ), inelastic scattering (includes reactions $M T=51$ to $M T=91$ ), and neutron disappearance $(M T=102$ to $M T=120)$. These calculations allow an easy assessment of the relative contributions of the different types of reactions to the total dpa cross sections.

It would be desirable to process the ENDF/B-VI cross sections into iron dpa cross sections in a way consistent with the previous processing of the ENDF/B-IV cross sections into dpa cross sections given in the ASTM standard E 693. However, the material temperature (for Doppler broadening of the resonances), the self-shielding applied to the cross sections, if any, and the weighting function, used to produce multigroup cross sections are not specified in the standard nor in the references to it. Hence, the following options were used in the present work: the damage energy cross sections were processed in the 640 extended SAND-II group structure, identical to the one used in ASTM E 693. The constant weighting function option was used in the NJOY module GROUPR, which produced group-averaged cross sections from the point data. The cross sections were generated for infinitely diluted material and for several values of the "background cross section," $\sigma_{0}$. The cross sections for the infinitely diluted material were highest and, therefore, conservative (i.e., predicting higher dpa values) with respect to the cross sections for the lower $\sigma_{0}$. For this reason the cross sections corresponding to the infinitely diluted material were selected and are reported in the next section. Two temperatures of the material, $300 \mathrm{~K}$ and $600 \mathrm{~K}$, were considered; however, the change in the temperature had negligible effect on the infinitely diluted cross sections, and consequently only one set is given. 
The damage energy cross sections were converted into the displacement cross sections following the recommendation of the International Atomic Energy Agency (IAEA) (Ref. 9), as was done in the generation of the ENDF/B-IV ASTM dpa cross sections. The IAEA recommendation is to calculate the number of displaced atoms by dividing the damage energy by $100 \mathrm{eV}$. In Doran's formulation (Ref. 3) the number of displaced atoms is obtained by multiplying the damage energy by a factor of $0.8 /\left(2 \times E_{d}\right)$, which is (for $E_{d}$ equal to $40 \mathrm{eV}$ ) equal to the IAEA conversion factor.

In the HEATR module of the NJOY version 94.105 code, the threshold energy, $\mathrm{E}_{\mathrm{R}}$, below which the Robinson partition function is set to zero, is equal to $25 \mathrm{eV}$. This means that PKAs with energies below $25 \mathrm{eV}$ do not contribute to the damage energy and consequently to the atom displacements. However, according to IAEA recommendations, the energy required to displace an iron atom from its lattice site is $40 \mathrm{eV}$. To achieve consistency, the $\mathrm{E}_{\mathrm{R}}$ in HEATR module was set to $40 \mathrm{eV}$. All the displacement cross sections reported in this work were generated with $E_{R}$ equal to $40 \mathrm{eV}$. The effect of changing the $E_{R}$ from 25 to $40 \mathrm{eV}$ is negligible, except in the narrow energy range just above the minimum neutron energy, at which the elastic scattering starts to contribute to the atom displacements. To achieve the energy transfer of 25 or $40 \mathrm{eV}$ in an elastic scattering on iron, the neutron must have the energy of at least $\sim 360 \mathrm{eV}$ or $\sim 580 \mathrm{eV}$, respectively. Since the contribution from elastic scattering rapidly increases above the threshold, the increase in $E_{R}$ results in large changes in the above-mentioned energy range, as will be shown in the next section.

\section{RESULTS AND DISCUSSION}

The effect of changing the cutoff energy, $E_{R}$, in HEATR from 25 to $40 \mathrm{eV}$ is illustrated in Figure 1 and Figure 2. The dpa from ASTM standard E 693 is also shown. Increasing the $E_{R}$ results in lower dpa cross sections in the region between $\sim 300 \mathrm{eV}$ and $2 \mathrm{keV}$. Outside this energy region the effect is negligible. The ENDF/B-VI dpa cross sections generated with $E_{R}$ set to $40 \mathrm{eV}$ is in better agreement with the dpa cross sections from ASTM standard E 693; however, the energy threshold used in the preparation of ENDF/B-IV dpa is not reported in the standard nor in its references. Using $E_{R}$ equal to $40 \mathrm{eV}$ in the calculation of the dpa is also consistent with the IAEA recommendation. For these two reasons the ENDF/B-VI dpa cross sections in the following are reported for $E_{R}$ of $40 \mathrm{eV}$.

The comparison of the displacement cross sections for Fe-56, for the infinitely diluted material and for different background cross sections, $\sigma_{0}$, is presented in Figure 3. Fully self-shielded cross sections correspond to the limit of $\sigma_{0} \rightarrow 0$, while the cross sections for the infinitely diluted material correspond to the limit of $\sigma_{0} \rightarrow \infty$. The cross sections for the infinitely diluted material are higher than the cross sections for any other $\sigma_{0}$. This implies that displacement cross sections for infinitely diluted iron will give higher - and, hence, conservative - dpa values. However, Figure 3 clearly shows that the effect of the self-shielding may be considerable, and further investigations may be necessary to produce displacement cross sections more appropriately self shielded for the conditions in the reactor PV wall.

The atom percent abundances of the iron isotopes, used to mix the dpa cross sections for natural iron, were taken from Reference 10, and were $5.85,91.75,2.12$, and $0.28 \%$ for the Fe-54, Fe-56, Fe-57, and Fe-58, respectively. The contributions of the individual isotopes to the displacement cross 
sections for natural iron are shown in Figures 4 and 5. The Fe-56 isotope contributes more than $90 \%$ to the displacement cross sections of the natural iron over most of the neutron energies, except in the region around $10 \mathrm{keV}$, where contributions from $\mathrm{Fe}-54$ and $\mathrm{Fe}-57$ are also considerable.

The contributions of different neutron reactions to the total dpa cross section for Fe-56 are shown in Figure 6. It can be seen that below the threshold of $\sim 580 \mathrm{eV}$, at which the elastic scattering starts to contribute, neutron disappearance reactions, or more precisely, the radiative capture $(n, \gamma)$ reaction is the only one that contributes to the dpa cross sections. Above the threshold the contribution from elastic scattering rapidly increases and makes up practically $100 \%$ of the dpa cross sections in the energy region between $\sim 1 \mathrm{keV}$ and $\sim 0.85 \mathrm{MeV}$. At neutron energies above the first excited level in $\mathrm{Fe}-56$ (which is at $0.8469 \mathrm{MeV}$ ), the contribution from inelastic scattering increases rapidly and reaches $\sim 70 \%$ of the dpa cross section at $\sim 7 \mathrm{MeV}$, then it decreases rapidly above $\sim 10 \mathrm{MeV}$. Above approximately $10 \mathrm{MeV}$ the contributions from "other reactions," which include $(n, 2 n),(n, n \alpha)$, and (n,np) reactions, start to become significant and reach approximately $50 \%$ at $20 \mathrm{MeV}$.

A comparison of the new ENDF/B-VI dpa cross sections with the ENDF/B-IV cross sections from the ASTM standard E 693 is presented in Figures 7 and 8. At the energies up to $\sim 100 \mathrm{eV}$ the new cross sections are $\sim 9 \%$ lower than the ENDF/B-IV. Above the threshold for the elastic scattering contribution, in the region around $10 \mathrm{keV}$, the new cross sections are higher than the old ones by $\sim 20 \sim 60 \%$. In this region the contributions from iron isotopes other than Fe-56 are important, and the reason for the differences may be that the ENDF/B-VI provides cross-section evaluations for separate isotopes. Such evaluations can be more detailed and more accurate than the evaluations for natural iron, which were given in ENDF/B-IV. In the region between $\sim 20 \mathrm{keV}$ and $\sim 0.8 \mathrm{MeV}$, the differences between the two dpa sets are between -20 and $+20 \%$. Above $\sim 0.8 \mathrm{MeV}$ the ENDF/B-VI dpa cross sections are a few percent smaller than the ENDF/B-VI cross sections, most probably because of reduced inelastic scattering cross sections in the ENDF/B-VI evaluation.

To assess the changes in the integral displacement rate (i.e., dpa/s) due to the changes from ENDF/B-IV to ENDF/B-VI displacement cross sections, the dpa rates were calculated through the thickness of the PV wall. The neutron spectra were taken from the analysis of HBR-2 (Ref. 11) with the Bugle-96 cross-section library (Ref. 12). The calculated spectra, at several locations in the PV wall, were folded with the ASTM and the new displacement cross sections. The two sets of the displacement cross sections were collapsed from the 640-group to the 47-group structure using the weighting spectrum, which consisted of the Watt fission spectrum matched to the $1 / \mathrm{E}$ tail at $0.5 \mathrm{MeV}$ and to the Maxwell thermal spectrum with the temperature of $560 \mathrm{~K}$ at $0.14 \mathrm{eV}$. The dpa rates are compared in Table 2. The dpa rate calculated with the ENDF/B-VI dpa cross sections is slightly lower than the ENDF/B-IV dpa rate at the PV inner wall; however, the ENDF/B-VI dpa rate attenuates slightly slower through the PV wall and is about $4 \%$ higher than the ENDF/B-IV dpa rate at the PV outer wall.

The new displacement cross sections for iron, based on ENDF/B-VI data are given in Table 3. 


\section{CONCLUSIONS}

The new displacement cross sections for iron were generated from the ENDF/B-VI data with the NJOY computer code. In the calculation of the displacement energy cross section the threshold in the energy partition function was set to $40 \mathrm{eV}$. New dpa cross sections are for infinitely diluted material (no self-shielding). The damage energy was converted into the number of displaced atoms following the IAEA recommendations, as was done before in the preparation of the dpa given in ASTM standard E 693.

The new ENDF/B-VI dpa cross sections typically agree with the "ASTM ENDF/B-IV" dpa cross sections to within $10 \%$ over most of the energy range; however, differences of up to $60 \%$ are present in the energy region around $10 \mathrm{keV}$. The effect of the change from ENDF/B-IV to the ENDF/B-VI iron-displacement cross sections on the total dpa rate was examined for the HBR-2 pressurized-water reactor. The differences in the dpa rates inside the PV wall were within $\sim 5 \%$. The ENDF/B-VI displacement cross sections result in slightly lower dpa rates in the softer neutron spectrum close to the PV inner wall, and up to $\sim 4 \%$ higher dpa rates in the region close to the PV outer surface. This result indicates that ENDF/B-VI displacement cross sections predict slightly less attenuation of the dpa through the PV wall. Similar changes in dpa rates are expected to be found in other pressurized water reactors: smaller differences will likely be found in thinner PVs and greater differences in thicker PVs.

The changes in the dpa rates caused by the new ENDF/B-VI displacement cross sections are relatively small and are, consequently, not expected to introduce a bias in embrittlement data bases if new results - based on ENDF/B-VI dpa - are added to the existing data, based on ENDF/B-IV cross sections. On the other hand, updating the iron-displacement cross sections to ENDF/B-VI is desirable, because it will establish consistency between the cross sections used for neutron transport calculations and the cross sections used to calculate the dpa. Therefore, it appears appropriate to recommend an update of the ASTM standard E 693 with the ENDF/B-VI displacement cross sections reported in this work. 


\section{REFERENCES}

1. W. F. Sheely, "Correlation of Radiation Damage to Steel with Neutron Spectrum," Nucl. Sci. Eng. 29,165-175 (1967).

2. J. D. Jenkins, "Primary-Recoil Atom Spectra from ENDF/B Data," Nucl. Sci. Eng., 41,155-163 (1970).

3. D. G. Doran and N. J. Graves, "Neutron Displacement Damage Cross Sections for Structural Materials," Irradiation Effects on the Microstructure and Properties of Metals, ASTM STP 611, American Society for Testing and Materials, 1976, pp. 463-482.

4. E 693 Standard Practice for Characterizing Neutron Exposures in Iron and Low Alloy Steels in Terms of Displacements Per Atom (DPA), E 706(ID), Annual Book of ASTM Standards, Sect. 12: Nuclear, Solar, and Geothermal Energy, 1998.

5. U.S. Nuclear Regulatory Commission Regulatory Guide 1.99, "Radiation Embrittlement of Reactor Vessel Materials," Revision 2, May 1988.

6. R. E. MacFarline and D. W. Muir, The NJOY Nuclear Data Processing System, Version 91, LA-1274-M, October 1994.

7. J. Lindhard, V. Nielsen, M. Scharff, and P. V. Thomsen, Mat. Fys. Medd. Dan. Vid. Selsk. 33 (10) (1963).

8. M. T. Robinson, “The Energy Dependence of Neutron Radiation Damage in Solids," p. 364 in Proc. Nuclear Fusion Reactors Conf., British Nuclear Energy Society, Culham Laboratory (1969).

9. "Recommendations for Displacement Calculations for Reactor/Accelerator Studies in Austenitic Steel," Nucl. Eng. Des. 33, 91, 1975.

10. Nuclides and Isotopes, Fifteenth Ed. 1996, General Electric Co., and KAPL, Inc.; available from GE Nuclear Energy, 175 Curtner Ave. M/C 948, San Jose, CA.

11. I. Remec and F. B. K. Kam, H. B. Robinson-2 Pressure Vessel Benchmark, NUREG/CR-6453, ORNL/TM-13204, U.S. Nuclear Regulatory Commission, 1998.

12. J. E. White et al., "Bugle-96: Coupled 47 Neutron, 20 Gamma-Ray Group Cross-Section Library Derived from ENDF/B-VI for LWR Shielding and Pressure Vessel Dosimetry Applications," RSICC Data Library Collection, DLC-185, Oak Ridge National Laboratory, March 1996. 
Table 1 Reactions processed in the calculation of the damage energy cross sections for iron

\begin{tabular}{|c|c|c|c|c|c|}
\hline \multirow[b]{2}{*}{ Reaction } & \multirow[b]{2}{*}{$\begin{array}{c}\mathrm{ENDF} / \mathrm{B} \\
\text { reaction } \\
\text { identifier } \\
(\mathrm{MT})\end{array}$} & \multicolumn{4}{|c|}{ Iron isotope } \\
\hline & & $\mathrm{Fe}-54$ & $\mathrm{Fe}-56$ & $\mathrm{Fe}-57$ & $\mathrm{Fe}-58$ \\
\hline $\begin{array}{c}\text { Elastic } \\
\text { scattering }\end{array}$ & 2 & $\mathrm{x}$ & $\mathrm{x}$ & $x$ & $\mathrm{x}$ \\
\hline$(n, 2 n)$ & 16 & $\mathrm{x}$ & $x$ & $\mathrm{x}$ & $\mathrm{x}$ \\
\hline$(\mathrm{n}, \mathrm{n} \alpha)$ & 22 & $\mathbf{x}$ & $\mathrm{x}$ & $\mathrm{x}$ & $\mathrm{x}$ \\
\hline$(\mathrm{n}, \mathrm{np})$ & 28 & $\mathrm{x}$ & $\mathrm{x}$ & $x$ & $\mathrm{x}$ \\
\hline$\left(\mathrm{n}, \mathrm{n}_{1}\right)^{*}$ & 51 & $x$ & $\mathrm{x}$ & $\mathrm{x}$ & $x$ \\
\hline$\left(\mathrm{n}, \mathrm{n}_{2}\right)$ & 52 & $\mathrm{x}$ & $\mathrm{x}$ & $\mathrm{x}$ & $\mathrm{x}$ \\
\hline$\left(n, n_{3}\right)$ & 53 & $\mathrm{x}$ & $\mathrm{x}$ & $\mathrm{x}$ & \\
\hline$\left(\mathrm{n}, \mathrm{n}_{4}\right)$ & 54 & $\mathrm{x}$ & $x$ & $x$ & \\
\hline$\left(\mathrm{n}, \mathrm{n}_{5}\right)$ & 55 & $\mathrm{x}$ & $\mathrm{x}$ & $\mathrm{x}$ & \\
\hline$\left(n, n_{6}\right)$ & 56 & $\mathrm{x}$ & $\mathrm{x}$ & & \\
\hline$\left(n, n_{7}\right)$ & 57 & $\mathrm{x}$ & $x$ & & \\
\hline$\left(\mathrm{n}, \mathrm{n}_{8}\right)$ & 58 & & $\mathrm{x}$ & & \\
\hline$\left(\mathrm{n}, \mathrm{n}_{9}\right)$ & 59 & & $\mathrm{x}$ & & \\
\hline$\left(\mathrm{n}, \mathrm{n}_{10}\right)$ & 60 & & $\mathrm{x}$ & & \\
\hline$\left(\mathrm{n}, \mathrm{n}_{11}\right)$ & 61 & & $\mathrm{x}$ & & \\
\hline$\left(\mathrm{n}, \mathrm{n}_{12}\right)$ & 62 & & $\mathrm{x}$ & & \\
\hline$\left(\mathrm{n}, \mathrm{n}_{13}\right)$ & 63 & & $\mathrm{x}$ & & \\
\hline$\left(\mathrm{n}, \mathrm{n}_{14}\right)$ & 64 & & $x$ & & \\
\hline$\left(\mathrm{n}, \mathrm{n}_{15}\right)$ & 65 & & $\mathrm{x}$ & & \\
\hline$\left(\mathrm{n}, \mathrm{n}_{16}\right)$ & 66 & & $\mathrm{x}$ & & \\
\hline
\end{tabular}


Table 1 (continued)

\begin{tabular}{|c|c|c|c|c|c|}
\hline \multirow[b]{2}{*}{ Reaction } & \multirow[b]{2}{*}{$\begin{array}{c}\text { ENDF/B } \\
\text { reaction } \\
\text { identifier } \\
(\mathrm{MT})\end{array}$} & \multicolumn{4}{|c|}{ Iron isotope } \\
\hline & & $\mathrm{Fe}-54$ & Fe-56 & $\mathrm{Fe}-57$ & $\mathrm{Fe}-58$ \\
\hline$\left(\mathrm{n}, \mathrm{n}_{17}\right)$ & 67 & & $\mathrm{x}$ & & \\
\hline$\left(n, n_{18}\right)$ & 68 & & $\mathrm{x}$ & & \\
\hline$\left(\mathrm{n}, \mathrm{n}_{19}\right)$ & 69 & & $\mathrm{x}$ & & \\
\hline$\left(\mathrm{n}, \mathrm{n}_{20}\right)$ & 70 & & $\mathrm{x}$ & & \\
\hline$\left(\mathrm{n}, \mathrm{n}_{21}\right)$ & 71 & & $\mathrm{x}$ & & \\
\hline$\left(\mathrm{n}, \mathrm{n}_{22}\right)$ & 72 & & $\mathrm{x}$ & & \\
\hline$\left(n, n_{23}\right)$ & 73 & & $\mathrm{x}$ & & \\
\hline$\left(\mathrm{n}, \mathrm{n}_{24}\right)$ & 74 & & $\mathrm{x}$ & & \\
\hline$\left(\mathrm{n}, \mathrm{n}_{25}\right)$ & 75 & & $\mathrm{x}$ & & \\
\hline$\left(\mathrm{n}, \mathrm{n}_{\mathrm{c}}\right)^{* *}$ & 91 & $\mathrm{x}$ & $\mathrm{x}$ & $\mathrm{x}$ & $\mathrm{x}$ \\
\hline$(\mathrm{n}, \gamma)$ & 102 & $\mathrm{x}$ & $\mathrm{x}$ & $\mathrm{x}$ & $\mathrm{x}$ \\
\hline$(n, p)$ & 103 & $\mathrm{x}$ & $\mathrm{x}$ & $\mathrm{x}$ & $\mathrm{x}$ \\
\hline$(\mathrm{n}, \mathrm{d})$ & 104 & $\mathrm{x}$ & $\mathrm{x}$ & & \\
\hline$(n, t)$ & 105 & & $\mathrm{x}$ & & \\
\hline$\left(\mathrm{n},{ }^{3} \mathrm{H}\right)$ & 106 & & $\mathrm{x}$ & & \\
\hline$(n, \alpha)$ & 107 & $\mathrm{x}$ & $\mathrm{x}$ & $\mathrm{x}$ & $\mathrm{x}$ \\
\hline
\end{tabular}

* Inelastic scattering leaving the nucleus in the first excited state. The symbol $\left(\mathrm{n}, \mathrm{n}_{\mathrm{i}}\right)$ denotes inelastic scattering, leaving the nucleus in the $i$ th excited state.

** Production of a single neutron in continuum not included in the discrete representations (MT 51-75). 
Table 2 Comparison of the dpa rates calculated with the ENDF/B-IV and ENDF/B-VI displacement cross sections for iron. The dpa rates are given versus distance from the pressure vessel inner wall

\begin{tabular}{|c|c|c|c|c|}
\hline & & A & B & Difference \\
\cline { 3 - 5 } Radius & $\begin{array}{c}\text { Distance from the } \\
\text { PV inner wall }\end{array}$ & ENDF/B-VI & ENDF/B-IV & $100^{*}(\mathrm{~A}-\mathrm{B}) / \mathrm{B}$ \\
\hline$(\mathrm{cm})$ & $(\mathrm{cm})$ & $(\mathrm{dpa} / \mathrm{s})$ & $(\mathrm{dpa} / \mathrm{s})$ & $\%$ \\
\hline $197.49^{*}$ & 0.00 & $4.80 \mathrm{E}-11$ & $4.82 \mathrm{E}-11$ & -0.4 \\
197.77 & 0.28 & $4.786 \mathrm{E}-11$ & $4.799 \mathrm{E}-11$ & -0.3 \\
198.96 & 1.47 & $4.482 \mathrm{E}-11$ & $4.477 \mathrm{E}-11$ & 0.1 \\
200.78 & 3.29 & $3.932 \mathrm{E}-11$ & $3.906 \mathrm{E}-11$ & 0.7 \\
202.60 & 5.11 & $3.371 \mathrm{E}-11$ & $3.331 \mathrm{E}-11$ & 1.2 \\
204.42 & 6.93 & $2.872 \mathrm{E}-11$ & $2.825 \mathrm{E}-11$ & 1.7 \\
206.23 & 8.75 & $2.448 \mathrm{E}-11$ & $2.397 \mathrm{E}-11$ & 2.1 \\
208.05 & 10.57 & $2.085 \mathrm{E}-11$ & $2.034 \mathrm{E}-11$ & 2.5 \\
209.87 & 12.38 & $1.769 \mathrm{E}-11$ & $1.719 \mathrm{E}-11$ & 2.9 \\
211.69 & 14.20 & $1.499 \mathrm{E}-11$ & $1.452 \mathrm{E}-11$ & 3.2 \\
213.51 & 16.02 & $1.258 \mathrm{E}-11$ & $1.215 \mathrm{E}-11$ & 3.5 \\
215.33 & 17.84 & $1.045 \mathrm{E}-11$ & $1.008 \mathrm{E}-11$ & 3.7 \\
217.14 & 19.66 & $8.547 \mathrm{E}-12$ & $8.223 \mathrm{E}-12$ & 3.9 \\
218.96 & 21.48 & $6.749 \mathrm{E}-12$ & $6.485 \mathrm{E}-12$ & 4.1 \\
220.78 & 23.30 & $5.017 \mathrm{E}-12$ & $4.818 \mathrm{E}-12$ & 4.1 \\
\hline
\end{tabular}

* PV inner radius 
Table 3 Displacement cross sections for iron derived from ENDF/B-VI data*

\begin{tabular}{|c|c|c|c|c|c|c|c|c|c|c|c|}
\hline Energy, MeV & Sigma, Bams & Energy, MeV & Sigma, barns & Energy, MeV & Sigma, barns & Energy, MeV & Sigma, barns & Energy, MeV & Sigma, barns & Energy, MeV & Sigma, barns \\
\hline $1.000 \mathrm{E}-10$ & $1.559 \mathrm{E}+02$ & $1.050 E-10$ & $1.521 E+02$ & $1.100 \mathrm{E}-10$ & $1.488 E+02$ & 1. $150 E-10$ & $1.456 \mathrm{E}+02$ & $1.200 E-10$ & $1.418 \mathrm{E}+02$ & $1.275 E-10$ & $1.377 E+02$ \\
\hline $1.350 \mathrm{E}-10$ & $1.341 E+02$ & $1.425 \mathrm{E}-10$ & $1.307 \mathrm{E}+02$ & $1.500 \mathrm{E}-10$ & $1.268 E+02$ & $1.600 \mathrm{E}-10$ & $1.229 E+02$ & $1.700 E-10$ & $1.194 E+02$ & $1.800 \mathrm{E}-10$ & $1.160 E+02$ \\
\hline $1.900 \mathrm{E}-10$ & $1.131 \mathrm{E}+02$ & 2.000E-10 & $1.102 E+02$ & $2.100 E-10$ & $1.077 E+02$ & $2.200 \mathrm{E}-10$ & $1.053 E+02$ & 2.300E-10 & $1.029 E+02$ & $2.400 E-10$ & $1.003 E+02$ \\
\hline $2.550 \mathrm{E}-10$ & $9.741 E+01$ & $2.700 \mathrm{E}-10$ & $9.524 \mathrm{E}+01$ & $2.800 E-10$ & $9.267 E+01$ & $3.000 E-10$ & $8.963 E+01$ & $3.200 E-10$ & $8.698 E+01$ & $3.400 \mathrm{E}-10$ & $8.437 E+01$ \\
\hline $3.600 E-10$ & $8.208 E+01$ & $3.800 E-10$ & $7.995 E+01$ & $4.000 E-10$ & $7.771 E+01$ & $4.250 E-10$ & $7.553 E+01$ & $4.500 \mathrm{E}-10$ & $7.338 E+01$ & $4.750 E-10$ & $7.146 \mathrm{E}+01$ \\
\hline $5.000 \mathrm{E}-10$ & $6.971 E+01$ & $5.250 \mathrm{E}-10$ & $6.814 \mathrm{E}+01$ & $5.500 E-10$ & 6.657E+01 & $5.750 E-10$ & $6.512 E+01$ & $6.000 E-10$ & $6.373 E+01$ & $6.300 \mathrm{E}-10$ & $6.222 E+01$ \\
\hline $6.600 \mathrm{E}-10$ & $6.074 E+01$ & $6.900 \mathrm{E}-10$ & $5.951 E+01$ & $7.200 \mathrm{E}-10$ & $5.813 E+01$ & $7.600 \mathrm{E}-10$ & $5.655 E+01$ & $8.000 E-10$ & $5.513 E+01$ & $8.400 E-10$ & $5.388 E+01$ \\
\hline 8.800E-10 & $5.263 E+01$ & $9.200 E-10$ & $5.146 E+01$ & $9.600 \mathrm{E}-10$ & $5.040 \mathrm{E}+01$ & $1.000 \mathrm{E}-09$ & $4.932 E+01$ & $1.050 E-09$ & $4.819 E+01$ & $1.100 \mathrm{E}-09$ & $4.706 \mathrm{E}+01$ \\
\hline $1.150 \mathrm{E}-09$ & $4.602 E+01$ & $1.200 E-09$ & $4.490 E+01$ & $1.275 E-09$ & $4.363 E+01$ & $1.350 E-09$ & $4.238 E+01$ & $1.425 \mathrm{E}-09$ & $4.131 E+01$ & $1.500 E-09$ & $4.011 E+01$ \\
\hline $1.600 \mathrm{E}-09$ & $3.889 E+01$ & $1.700 \mathrm{E}-09$ & $3.777 E+01$ & $1.800 \mathrm{E}-0 \mathrm{~S}$ & $3.669 E+01$ & $1.900 \mathrm{E}-09$ & $3.574 \mathrm{E}+01$ & $2.000 E-09$ & $3.488 E+01$ & $2.100 \mathrm{E}-09$ & $3.408 E+01$ \\
\hline $2.200 E-09$ & $3.328 \mathrm{E}+01$ & $2.300 \mathrm{E}-09$ & $3.258 E+01$ & $2.400 \mathrm{E}-09$ & $3.178 \mathrm{E}+01$ & $2.550 E-09$ & $3.082 E+01$ & $2.700 \mathrm{E}-09$ & $3.012 \mathrm{E}+01$ & $2.800 \mathrm{E}-09$ & $2.937 E+01$ \\
\hline $3.000 \mathrm{E}-09$ & $2.837 E+01$ & $3.200 E-09$ & $2.750 E+01$ & $3.400 E-09$ & $2.671 E+01$ & $3.600 E-09$ & $2.595 \mathrm{E}+01$ & $3.800 E-09$ & $2.527 E+01$ & $4.000 \mathrm{E}-09$ & $2.460 E+01$ \\
\hline $4.250 E-09$ & $2.389 E+01$ & 4.500E-09 & $2.320 E+01$ & 4.750E-09 & $2.262 E+01$ & $5.000 \mathrm{E}-09$ & $2.209 E+01$ & $5.250 \mathrm{E}-09$ & $2.155 E+01$ & $5.500 \mathrm{E}-09$ & $2.105 E+01$ \\
\hline $5.750 E-09$ & $2.062 E+01$ & $6.000 E-09$ & $2.014 E+01$ & $6.300 E-09$ & $1.966 E+01$ & $6.600 \mathrm{E}-09$ & $1.924 E+01$ & $6.900 \mathrm{E}-09$ & $1.882 E+01$ & $7.200 E-09$ & $1.835 E+01$ \\
\hline 7.600E-09 & $1.787 E+01$ & $8.000 E-09$ & $1.745 E+01$ & $8,400 E-09$ & $1.704 \mathrm{E}+01$ & $8.800 E-09$ & $1.664 \mathrm{E}+01$ & $9.200 \mathrm{E}-09$ & $1.630 E+01$ & $9.600 \mathrm{E}-09$ & $1.598 E+01$ \\
\hline $1.000 \mathrm{E}-08$ & $1.561 E+01$ & $1.050 E-08$ & $1.523 E+01$ & $1.100 E-08$ & $1.491 E+01$ & $1.150 \mathrm{E}-08$ & $1.460 \mathrm{E}+01$ & $1.200 E-08$ & $1.421 E+01$ & $1.275 E-08$ & +01 \\
\hline $1,350 E-08$ & $1.342 E+01$ & $1.425 \mathrm{E}-08$ & $1.306 E+01$ & $1.500 \mathrm{E}-08$ & $1.268 E+01$ & $1.600 \mathrm{E}-08$ & $1.231 \mathrm{E}+01$ & $1.700 \mathrm{E}-08$ & $1.195 E+01$ & $1.800 \mathrm{E}-08$ & $1.161 E+01$ \\
\hline $1.900 \mathrm{E}-08$ & $1.132 E+01$ & $2.000 \mathrm{E}-08$ & $1.105 E+01$ & $2.100 \mathrm{E}-08$ & $1.078 E+01$ & $2.200 E-08$ & $1.053 E+01$ & $2.300 E-08$ & $1.032 E+01$ & $2.400 E-08$ & $E+04$ \\
\hline $2.550 \mathrm{E}-08$ & $9.761 E+00$ & $2.700 \mathrm{E}-08$ & $9.544 E+00$ & 2.800E-08 & $9.285 E+00$ & 3.000E-08 & $8.983 E+00$ & $3.200 \mathrm{E}-08$ & $8.705 E+00$ & $3.400 E-08$ & $8.451 E+00$ \\
\hline $3.600 E-08$ & $8.222 E+00$ & $3.800 E-08$ & $8.005 E+\infty 0$ & $4.000 E-08$ & $7.788 E+00$ & $4.250 \mathrm{E}-08$ & 7.56 & 4.500E-08 & $7.362 E+00$ & -08 & $=+\infty$ \\
\hline $5.000 \mathrm{E}-08$ & $6.993 E+00$ & $5.250 E-08$ & $6.834 E+00$ & $5.500 E-08$ & $6.677 E+00$ & $5.750 \mathrm{E}-08$ & $6.528 E+00$ & $6.000 E-08$ & $6.390 E+00$ & $6.300 E-08$ & $6.243 E+00$ \\
\hline $6.600 \mathrm{E}-08$ & $6.096 E+00$ & $6.900 \mathrm{E}-08$ & $5.962 E+00$ & $7.200 E-08$ & $5.823 E+00$ & $7.600 E-08$ & $5.668 E+00$ & $8.000 E-08$ & $5.532 E+00$ & $8.400 E-08$ & $5.400 E+00$ \\
\hline $8.800 \mathrm{E}-08$ & $5.281 E+00$ & $9.200 E-08$ & $5.167 E+00$ & $9.600 E-08$ & $5.064 E+00$ & $1.000 E-07$ & $4.955 E+\infty 0$ & $1.050 \mathrm{E}-07$ & $4.835 \mathrm{E}+00$ & $1.100 \mathrm{E}-07$ & $4.727 E+00$ \\
\hline $1.150 \mathrm{E}-07$ & $4.631 E+00$ & $1.200 \mathrm{E}-07$ & $4.515 E+00$ & $1.275 E-07$ & $4.382 E+00$ & $1.350 \mathrm{E}-07$ & 4.26 & 1.425E-07 & $=+\infty$ & 1.500 & $=+\infty$ \\
\hline $1.600 \mathrm{E}-07$ & $3.913 E+00$ & $1.700 E-07$ & $3.806 E+00$ & $1.800 E-07$ & $3.701 E+00$ & $1.900 \mathrm{E}-07$ & $3.602 \mathrm{E}+00$ & $2.000 \mathrm{E}-07$ & $3.516 \mathrm{E}+00$ & 2. $100 \mathrm{E}-07$ & $3.437 E+00$ \\
\hline $2.200 \mathrm{E}-07$ & $3.358 E+00$ & 2.300E-07 & $3.291 E+00$ & $2.400 E-07$ & $3.212 E+\infty 0$ & $2.550 E-07$ & $3.118 E+\infty 0$ & 2.700E-07 & 3.044 & $2.800 \mathrm{E}-07$ & 2.968 \\
\hline 3.000E-07 & $2.872 \mathrm{E}+00$ & 3.200E-07 & $2.788 \mathrm{E}+00$ & $3.400 E-07$ & $2.706 E+00$ & $3.600 \mathrm{E}-07$ & $2.634 \mathrm{E}+00$ & 3.800E-07 & $2.563 \mathrm{E}+\infty 0$ & 4.000 & $2.484 E+00$ \\
\hline $4.250 \mathrm{E}-07$ & $2.405 E+00$ & $4.500 E-07$ & $2.341 E+00$ & 4.750E-07 & $2.278 E+00$ & $5.000 E-07$ & $2.222 E+00$ & 5.250E-07 & $2.172 E+00$ & 5.500 & 2.122 \\
\hline $5.750 \mathrm{E}-07$ & $2.074 E+00$ & $6.000 \mathrm{E}-07$ & $2.029 \mathrm{E}+00$ & $6.300 E-07$ & $1.981 E+00$ & $6.600 \mathrm{E}-07$ & $1.934 E+00$ & 6.900E-07 & $1.893 \mathrm{E}+0 \mathrm{D}$ & $7.200 E-07$ & $1.848 E+00$ \\
\hline $7.600 \mathrm{E}-07$ & $1.801 E+00$ & $8.000 E-07$ & $1.755 E+00$ & $8.400 E-07$ & $1.713 E+00$ & 8.800E-07 & $1.676 E+\infty$ & $9.200 \mathrm{E}-07$ & $1.641 E+\infty 0$ & $9.600 \mathrm{E}-07$ & 1.606 \\
\hline $1.000 \mathrm{E}-06$ & $1.569 \mathrm{E}+00$ & $1.050 E-06$ & $1.534 E+00$ & $1,100 E-06$ & $1.498 \mathrm{E}+00$ & $1.150 \mathrm{E}-06$ & $1.466 \mathrm{E}+00$ & $1.200 \mathrm{E}-06$ & $1.430 E+\infty 0$ & 1.275 & $1.386 E+00$ \\
\hline $1.350 \mathrm{E}-06$ & $1.348 E+00$ & $1.425 E-06$ & $1.314 E+\infty 0$ & $1.500 \mathrm{E}-06$ & $1.277 E+00$ & $1.600 E-06$ & $1.236 \mathrm{E}+00$ & $1.700 E-06$ & $1.202 E+00$ & $1.800 \mathrm{E}-06$ & $1.168 \mathrm{E}+00$ \\
\hline $1.900 E-06$ & 1.137E+00 & $2.000 E-06$ & $1.110 E+00$ & $2.100 \mathrm{E}-06$ & $1.084 E+00$ & $2.200 \mathrm{E}-06$ & $1.058 E+\infty 0$ & $2.300 \mathrm{E}-06$ & $1.036 E+\infty 0$ & 2.400 & $1.010 \mathrm{E}+00$ \\
\hline 2.550E-06 & $9.790 E-01$ & 2.700E-06 & 9.564E-01 & 2.800E-06 & $9.316 E-01$ & $3.000 E-06$ & $9.013 \mathrm{E}-01$ & $3.200 E-06$ & 8.723E-01 & $3.400 \mathrm{E}-06$ & $8.476 E-01$ \\
\hline $3.600 \mathrm{E}-06$ & 8.249E-01 & $3.800 E-06$ & $8.024 E-01$ & $4.000 E-05$ & $7.804 \mathrm{E}-01$ & 4.250E-06 & $7.575 E-01$ & $4.500 \mathrm{E}-06$ & 7.366 & 4.75 & 7.17 \\
\hline $5.000 E-06$ & $6.992 E-01$ & $5.250 \mathrm{E}-06$ & 6.823E-01 & 5.500E-06 & $6.668 \mathrm{E}-01$ & 5.750E-06 & $6.530 \mathrm{E}-01$ & $6.000 E-06$ & 6.381E-01 & $6.300 \mathrm{E}-06$ & $6.223 E-01$ \\
\hline $6.600 E-06$ & $6.088 E-01$ & $6.900 E-06$ & 5.959E-01 & $7.200 E-06$ & 5.809E-01 & $7.600 E-06$ & $5.656 \mathrm{E}=01$ & $8.000 E-06$ & 5.521E-01 & 8.40 & 5.38 \\
\hline $8.800 E-06$ & 5.257E-01 & $9.200 E-06$ & 5.146E-01 & $9.600 \mathrm{E}-06$ & 5.040E-01 & 1.000 E-05 & 4.921E-01 & $1.050 E-05$ & $4.802 \mathrm{E}-01$ & $1.100 \mathrm{E}-05$ & 4.691E-01 \\
\hline $1.150 E-05$ & 4.593E-01 & $1.200 \mathrm{E}-05$ & 4.473E-01 & $1.275 \mathrm{E}-05$ & 4.338E-01 & $1.350 E=05$ & 4.221E-01 & 1.425E-05 & 4.107E-01 & 1.500 & 3.98 \\
\hline $1.600 E-05$ & 3.863E-01 & $1.700 \mathrm{E}-05$ & $3.744 E-01$ & $1.800 \mathrm{E}-05$ & 3.637E-01 & $1.900 E=05$ & $3.542 E-01$ & $2.000 E-05$ & $3.448 E-01$ & $2.100 \mathrm{E}-05$ & 3.363E-01 \\
\hline $2.200 \mathrm{E}-05$ & $3.284 E-01$ & $2.300 E-05$ & 3.214E-01 & 2.400E-05 & 3.128E-01 & 2.550E-05 & $3.030 E-01$ & 2.70 & 2.958E-01 & 2.80 & 2.87 \\
\hline $3.000 \mathrm{E}-05$ & 2.777E-01 & 3.200 E-05 & $2.689 \mathrm{E}-01$ & $3.400 E-05$ & $2.606 \mathrm{E}-01$ & $3.600 \mathrm{E}-05$ & $2.531 E-01$ & 3.800E-05 & 2.462E-01 & $4.000 \mathrm{E}-05$ & $2.387 E-01$ \\
\hline $4.250 \mathrm{E}-05$ & $2.312 \mathrm{E}-01$ & $4.500 E-05$ & 2.245E-01 & $4.750 E-05$ & $2.183 E-01$ & $5.000 E-05$ & $2.122 E-01$ & $5.250 E-05$ & 2.067E-01 & 5.50 & 2.01 \\
\hline $5.750 E-05$ & $1.970 E-01$ & $6.000 E-05$ & $1.920 E-01$ & $6.300 \mathrm{E}-05$ & $1.871 E-01$ & 6.600E-05 & $1,826 \mathrm{E}-01$ & $6.900 \mathrm{E}-05$ & $1.780 E-01$ & $7.200 \mathrm{E}-05$ & $1.733 E-01$ \\
\hline $7.600 E-05$ & $1.682 \mathrm{E}-01$ & $8.000 \mathrm{E}-05$ & 1.634E-01 & 8.400E-05 & $1.591 \mathrm{E}-01$ & $8.800 E-05$ & $1.549 \mathrm{E}-01$ & $9.200 E-05$ & 1.513E-01 & $9.600 \mathrm{E}-05$ & 1.477 \\
\hline $1.000 \mathrm{E}-04$ & $1.437 \mathrm{E}-01$ & $1.050 E-04$ & 1.397E-01 & $1.100 E-04$ & $1.361 E-01$ & $1.150 \mathrm{E}-04$ & $1.326 \mathrm{E}-01$ & $1.200 \mathrm{E}-04$ & $1.284 \mathrm{E}-01$ & $1.275 \mathrm{E}-04$ & $1.241 \mathrm{E}-01$ \\
\hline $1.350 \mathrm{E}-04$ & $1.199 E-01$ & $1.425 E-04$ & $1.160 E-01$ & $1.500 E-04$ & $1.120 \mathrm{E}-01$ & $1.600 \mathrm{E}-04$ & $1.076 \mathrm{E}-01$ & $1.700 \mathrm{E}-04$ & $1.037 \mathrm{E}-01$ & $1.800 \mathrm{E}-04$ & $1.001 E-01$ \\
\hline $1.900 \mathrm{E}-04$ & $9.677 E-02$ & 2.000E-04 & 9.353E-02 & 2.100E-04 & $9.065 E-02$ & $2.200 \mathrm{E}-04$ & 1.033E-01 & $2.300 E-04$ & $1.007 \mathrm{E}-01$ & $2.400 \mathrm{E}-04$ & 8.23BE-02 \\
\hline $2.550 \mathrm{E}-04$ & 7.908E-02 & $2.700 E-04$ & 7.647E-02 & $2.800 E-04$ & 7.375E-02 & $3.000 E-04$ & 7.031E-02 & $3.200 E-04$ & 6.718E-02 & $3.400 \mathrm{E}-04$ & $1.570 \mathrm{E}-01$ \\
\hline $3.600 \mathrm{E}-04$ & $7.281 E-02$ & $3.800 \mathrm{E}-04$ & $5.914 \mathrm{E}-02$ & $4.000 E-04$ & $5.650 E-02$ & $4.250 \mathrm{E}=04$ & 5.387E-02 & $4.500 \mathrm{E}-04$ & 5.152E-02 & 4.750E-04 & $4.925 E-02$ \\
\hline $5.000 E-04$ & 5.277E-02 & $5.250 E-04$ & $6.528 \mathrm{E}-02$ & $5.500 E-04$ & $8.406 \mathrm{E}-02$ & $5.750 \mathrm{E}-04$ & $1.568 \mathrm{E}-01$ & $6.000 E-04$ & $2.778 \mathrm{E}-01$ & 6.300E-04 & 4.136E-01 \\
\hline $6.600 \mathrm{E}-04$ & $5.521 E-01$ & $6.900 \mathrm{E}-04$ & $6.811 \mathrm{E}-01$ & $7.200 \mathrm{E}-04$ & $8.341 \mathrm{E}-01$ & $7.600 \mathrm{E}-04$ & $1.013 E+00$ & $8.000 E-04$ & $1.174 \mathrm{E}+00$ & 8.400E-04 & $1.325 E+00$ \\
\hline B.800E-04 & $1.476 E+\infty 0$ & $9.200 \mathrm{E}-04$ & $1.623 E+00$ & $9.600 \mathrm{E}-04$ & $1.752 E+00$ & $1.000 \mathrm{E}-03$ & $1.888 E+00$ & $1.050 \mathrm{E}-03$ & $2.041 E+00$ & $1.100 \mathrm{E}-03$ & $1.119 E+01$ \\
\hline $1.150 \mathrm{E}-03$ & $8.554 E+00$ & $1.200 \mathrm{E}-03$ & $2.486 E+00$ & $1.275 E-03$ & $2.672 \mathrm{E}+00$ & $1.350 \mathrm{E}-03$ & $2.852 E+00$ & $1.425 \mathrm{E}-03$ & $3.003 E+00$ & $1.500 \mathrm{E}-03$ & $3.181 \mathrm{E}+00$ \\
\hline $1.600 E-03$ & $3.540 E+00$ & $1.700 \mathrm{E}-03$ & $3.597 E+00$ & $1.800 E-03$ & $3.773 E+00$ & $1.900 E-03$ & $3.943 E+00$ & $2.000 E-03$ & $4.109 \mathrm{E}+00$ & $2.100 \mathrm{E}-03$ & $4.270 E+00$ \\
\hline $2.200 E-03$ & $4.435 E+00$ & $2.300 E-03$ & $4.636 E+\infty 0$ & 2.400E-03 & $4.813 E+00$ & $2.550 E-03$ & $5.032 \mathrm{E}+00$ & $2.700 \mathrm{E}-03$ & $5.205 E+00$ & $2.800 E-03$ & $5.407 E+00$ \\
\hline $3.000 E-03$ & $5.666 E+0.0$ & $3.200 E-03$ & $5.918 E+00$ & $3.400 \mathrm{E}-03$ & $6.179 E+00$ & $3.600 E-03$ & $6.693 E+00$ & $3.800 \mathrm{E}-03$ & $9.399 E+00$ & $4.000 \mathrm{E}-03$ & $8.664 E+00$ \\
\hline $4.250 E-03$ & $7.805 E+00$ & $4.500 E-03$ & $7.929 E+00$ & $4.750 \mathrm{E}-03$ & $8.216 E+00$ & $5.000 E-03$ & $8.612 \mathrm{E}+00$ & $5.250 E-03$ & $9.219 E+00$ & $5.500 \mathrm{E}-03$ & $1.028 E+01$ \\
\hline $5.750 E-03$ & $1.286 E+01$ & $6.000 E-03$ & $2.073 E+01$ & $6.300 \mathrm{E}-03$ & $1.923 E+01$ & $6.600 \mathrm{E}-03$ & $1.825 E+01$ & $6.900 \mathrm{E}-03$ & 2.399E+01 & $7.200 \mathrm{E}-03$ & $3.890 E+01$ \\
\hline $7.600 \mathrm{E}-03$ & $5.568 E+01$ & $8.000 \mathrm{E}-03$ & $4.794 E+01$ & $8.400 E-03$ & $3.465 E+01$ & 8.800E-03 & $2.692 \mathrm{E}+01$ & $9.200 E-03$ & $2.327 E+01$ & $9.600 \mathrm{E}-03$ & $2.045 E+01$ \\
\hline $1.000 \mathrm{E}-02$ & $1.980 E+01$ & $1.050 \mathrm{E}-02$ & $1.826 \mathrm{E}+01$ & $1,100 \mathrm{E}-02$ & $1.838 \mathrm{E}+01$ & $1.150 E-02$ & $1.669 E+01$ & $1.200 \mathrm{E}-02$ & $1.631 E+01$ & $1.275 \mathrm{E}-02$ & $1.590 \mathrm{E}+01$ \\
\hline
\end{tabular}


Table 3 (continued)

\begin{tabular}{|c|c|c|c|c|c|c|c|c|c|c|c|}
\hline ergy, MeV & Sigma, Barns & Energy, MeV & na, barns & Energy, Mev & Sigma, barns & Energy, MeV & Sigma, barns & MeV & barns & $\mathrm{MeV}$ & S \\
\hline & & & & & & & & & & & \\
\hline & & & & & & & & & $4.420 \mathrm{E}+00$ & 02 & $247 E+00$ \\
\hline $2.550 E-02$ & $E+01$ & 2.7 & $+2 E+02$ & 2.800E-02 & $10 E+02$ & $=02$ & $382 E+02$ & & +01 & 02 & $7.510 E+01$ \\
\hline$E-02$ & $E+01$ & 3.8 & $E+01$ & $4.000 \mathrm{E}-02$ & +01 & $4.250 \mathrm{E}-02$ & $47 E+01$ & & & & \\
\hline $5.000 \mathrm{E}-02$ & $8.076 E+01$ & $5.250 \mathrm{E}-02$ & $78 E+01$ & $5.500 \mathrm{E}-02$ & $60 E+01$ & $5.750 \mathrm{E}-02$ & 176E+01 & $6.000 \mathrm{E}-02$ & & & \\
\hline $6.600 \mathrm{E}-02$ & $4.110 \mathrm{E}+01$ & $6.900 \mathrm{E}-02$ & $25 \mathrm{E}+01$ & $7.200 E-02$ & $2 E+02$ & $7.600 \mathrm{E}-02$ & $7.281 E+01$ & $8.000 \mathrm{E}-02$ & $1.415 E+02$ & $8.400 \mathrm{E}-02$ & $2.744 E+02$ \\
\hline $8.800 \mathrm{E}-02$ & $1.384 E+02$ & $9.200 \mathrm{E}-02$ & 1.04 & 9.60 & & & & $E-01$ & $7.843 E+01$ & -01 & $810 E+01$ \\
\hline 1.150E-01 & 6.04 & 1.20 & $7.055 E+01$ & 1.275E-01 & & & $2.540 \mathrm{E}+02$ & $E-01$ & 2.93 & & +02 \\
\hline $1.600 \mathrm{E}-01$ & $1.223 \mathrm{E}+02$ & 1.700 & $1.565 \mathrm{E}+02$ & 1.80 & 2.43 & 1.90 & $3.714 E+02$ & $=-01$ & $2.055 E+02$ & 2.10 & \\
\hline 2.200E-01 & 3.08 & 2.3 & & & & & & & 02 & & \\
\hline $3.000 \mathrm{E}-01$ & & 3.200 & .02 & 3.400E-01 & & $3.600 E-01$ & +02 & 3.800 & 02 & & \\
\hline-01 & & 4.50 & +02 & 4.75 & $=+02$ & $5.000 E-01$ & $=+02$ & & +02 & & +02 \\
\hline-01 & $2.643 E+02$ & $6.000 \mathrm{E}-01$ & $1.908 \mathrm{E}+02$ & -01 & +02 & 6.600 & $5.298 E+02$ & & & & +02 \\
\hline $7.600 \mathrm{E}-01$ & $6.274 E+02$ & 8.00 & 4.27 & 8.40 & $=+02$ & $8.800 \mathrm{E}-01$ & $3.272 E+02$ & & 2.78 & & +02 \\
\hline $1.000 E+00$ & $4.984 E+02$ & $1.100 E+\infty 0$ & $4.778 \mathrm{E}+02$ & $1.200 E+00$ & $=02$ & $1.300 \mathrm{E}+00$ & $6.161 E+02$ & $+\infty$ & 7.15 & & \\
\hline $1.600 E+00$ & $7.588 E+02$ & $1.700 E+\infty 0$ & $7.855 E+02$ & $1.800 E+00$ & +02 & $E+\infty$ & $9.885 E+02$ & & 9.2 & & 02 \\
\hline$+\infty$ & $9.700 E+02$ & 2.30 & $E+03$ & $2.400 E+00$ & $=+03$ & $E+00$ & $E+03$ & .00 & 1.15 & 2.7 & 03 \\
\hline & 1.27 & 00 & & & & & & & 1.3 & & 03 \\
\hline & & 3 & & & & & & & & & \\
\hline$+\infty$ & 1.52 & 4.10 & 1.56 & 4.20 & & & & & & & \\
\hline$+\infty$ & 1.60 & 4.70 & 1.61 & 4.80 & 1.65 & 4.96 & & & & & \\
\hline$+\infty 0$ & 1.68 & 5.30 & +03 & 5.400 & 1.7 & 5.50 & 1.73 & 5.60 & 1.76 & 5.70 & +03 \\
\hline$+\infty 0$ & 1.768 & 5.900 & $E+03$ & 6.000 & .03 & $+\infty 0$ & +03 & $+\infty$ & 1.81 & 6.30 & 1.85 \\
\hline & 1.85 & so & 03 & 6. & & 6.7 & & & 1.91 & & 03 \\
\hline 00 & 1.915 & 1.106 & 03 & 7.20 & & 7.30 & & & -03 & & +03 \\
\hline$E+\infty$ & 1.97 & 7.700 & $1.989 E+03$ & 7.800 & & & & -00 & 2.00 & & \\
\hline & & 8.3 & & & & & & & & & \\
\hline+00 & 2.0 & 8.90 & 03 & 9.00 & 03 & 9.10 & 03 & & & & \\
\hline$+\infty$ & 03 & 9.50 & +03 & $\infty$ & & 100 & 103 & $+\infty$ & -03 & -00 & +03 \\
\hline+01 & & -01 & & & & 1.03 & & & & & \\
\hline +01 & & 11 & 2.337 & 1.08 & & & & & & & \\
\hline & & & & & & & & & & & \\
\hline & & 1 & & & & & & & & & \\
\hline+01 & 03 & 21 & & $1.26 \mathrm{c}$ & & & & & & & \\
\hline$E+01$ & +03 & $1.310 E+01$ & $2.645 \mathrm{E}+03$ & $1.320 E+01$ & 2.655 & & r03 & 01 & $2.686 \mathrm{E}$ & 1.35 & 2.699 \\
\hline & & & & & & & & & & & 03 \\
\hline & & & & & & & & & & & \\
\hline & & & & $1.500 E \div 01$ & & & & & & & \\
\hline & 03 & 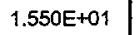 & & $1.560 E+01$ & & 1.57 & & +01 & & 1.59 & \\
\hline $1.600 \mathrm{E}+01$ & 103 & $1.610 E+01$ & $2.815 E+03$ & $1.620 \mathrm{E}+01$ & $2.817 E+03$ & $1.630 \mathrm{E}+01$ & $2.818 E+03$ & $1.640 \mathrm{E}+01$ & 2.82 & 1.650 & $2.820 \mathrm{E}+03$ \\
\hline $1.660 E+01$ & $2.820 E+03$ & $1.670 \mathrm{E}+01$ & $2.820 E+03$ & $1.680 E+01$ & $2.820 E+03$ & $1.690 \mathrm{E}+01$ & $2.820 E+03$ & $1.700 E+01$ & $2.824 E+03$ & 1.71 & $2.832 E+03$ \\
\hline+01 & 03 & +01 & $E+03$ & & & $0 E+01$ & +03 & $E+01$ & 33 & 01 & $2.879 E+03$ \\
\hline & & & & & & & & & & & \\
\hline & & & & & & & & & & & \\
\hline & & & & & & 1.93 & & 01 & $3,020 E+03$ & $1.95 \mathrm{C}$ & $3.026 E+03$ \\
\hline $1.960 \mathrm{E}$ & $3.032 E+03$ & $1.970 E+01$ & $3.038 E+03$ & $1.980 \mathrm{E}+01$ & $3.045 E+03$ & $1.990 E+01$ & $3.051 E+03$ & & & & \\
\hline
\end{tabular}

*Energies given are lower bounds of each group. Cross sections are given in units of $10^{-24} \mathrm{~cm}^{2}$. 


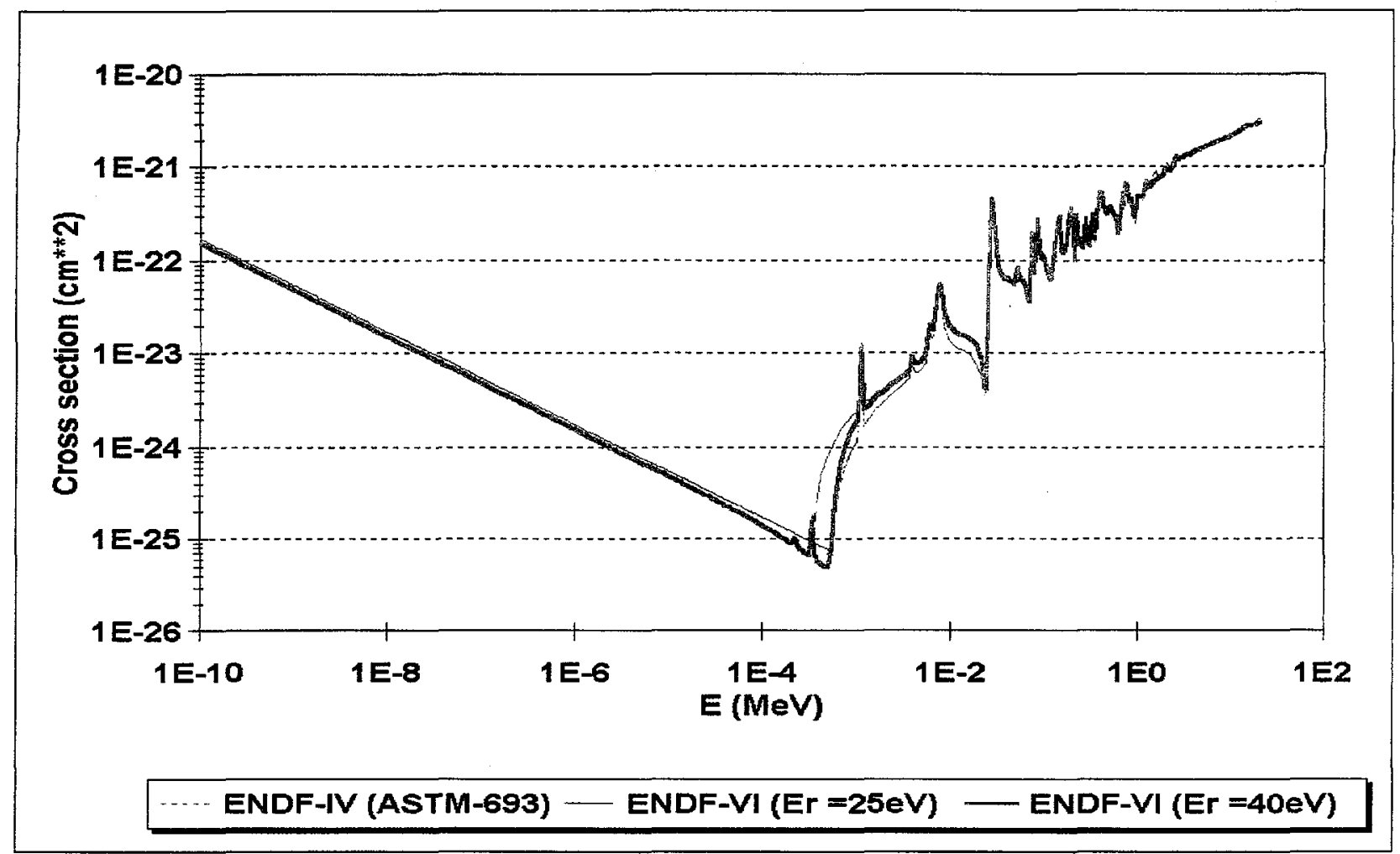

Figure 1 An illustration of the effect of changing the cutoff energy $E_{R}$ in HEATR from 25 to $40 \mathrm{eV}$ on the iron-displacement cross sections. The displacement cross sections from ASTM standard E 693 are also shown 


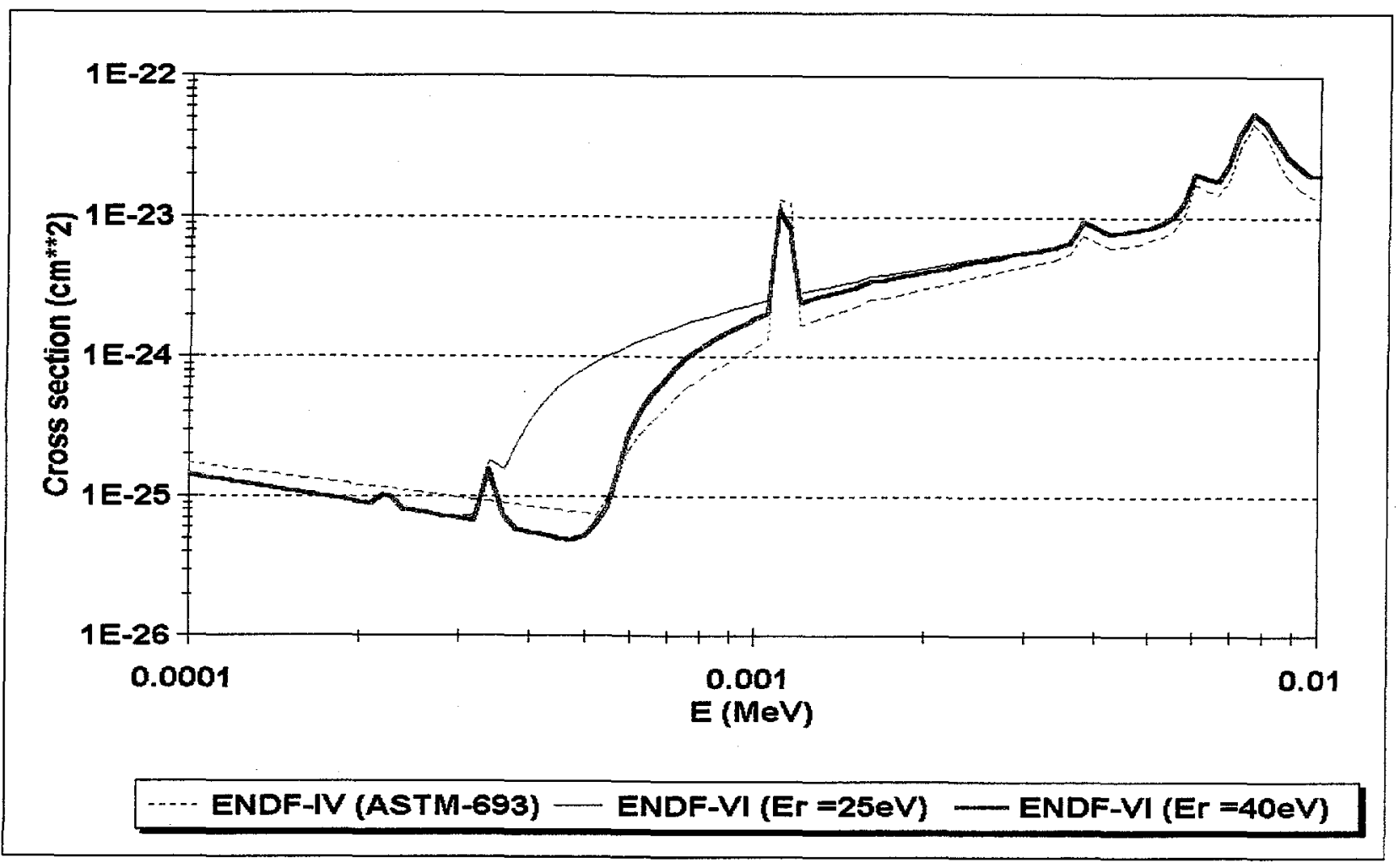

Figure 2 Details of the energy region in which the change of the $E_{R}$ results in the largest change in the displacement cross sections 


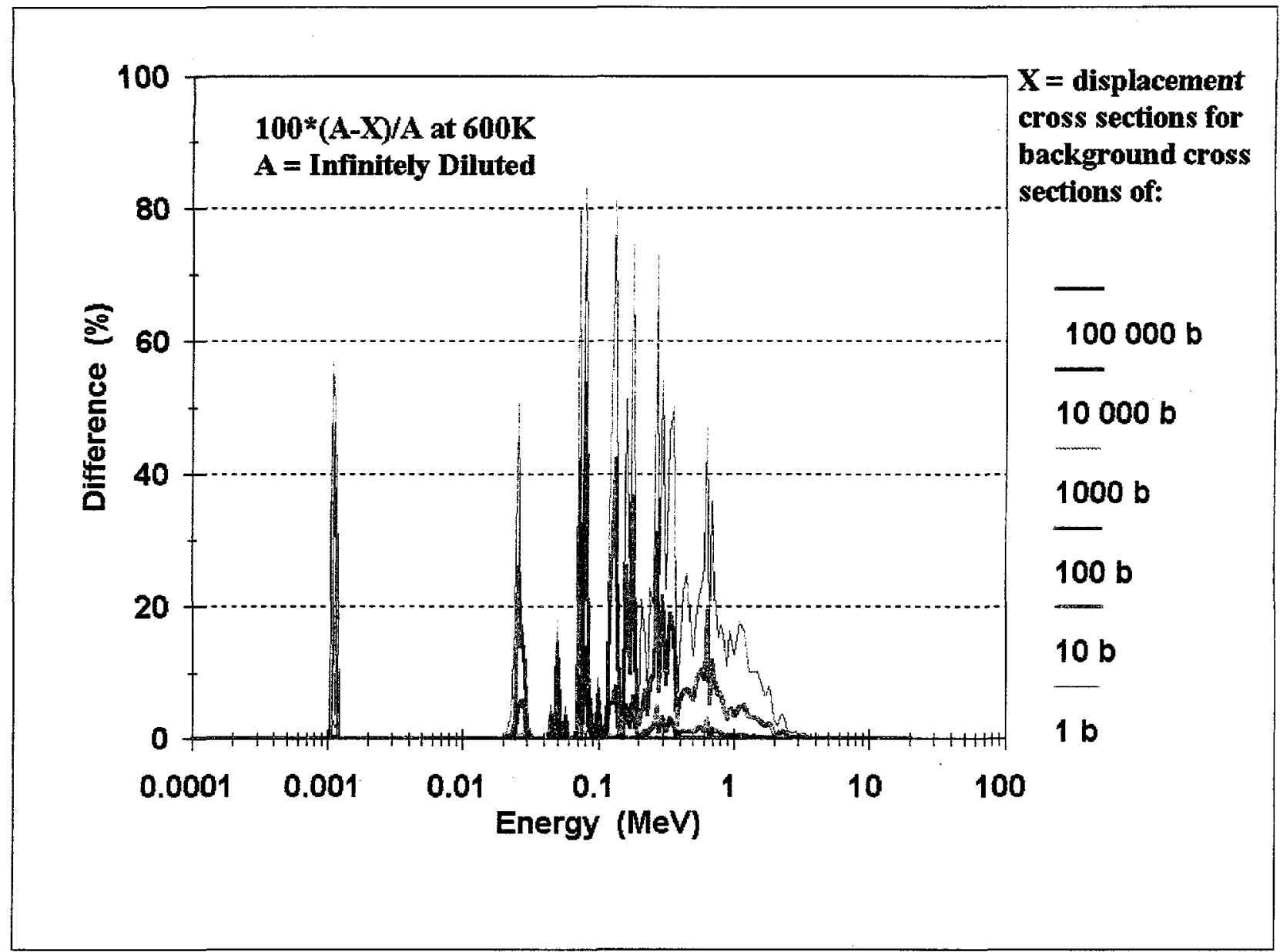

Figure 3 Comparison of the displacement cross sections for Fe-56 for the infinitely diluted material and for different background cross sections, $\sigma_{0}$ 


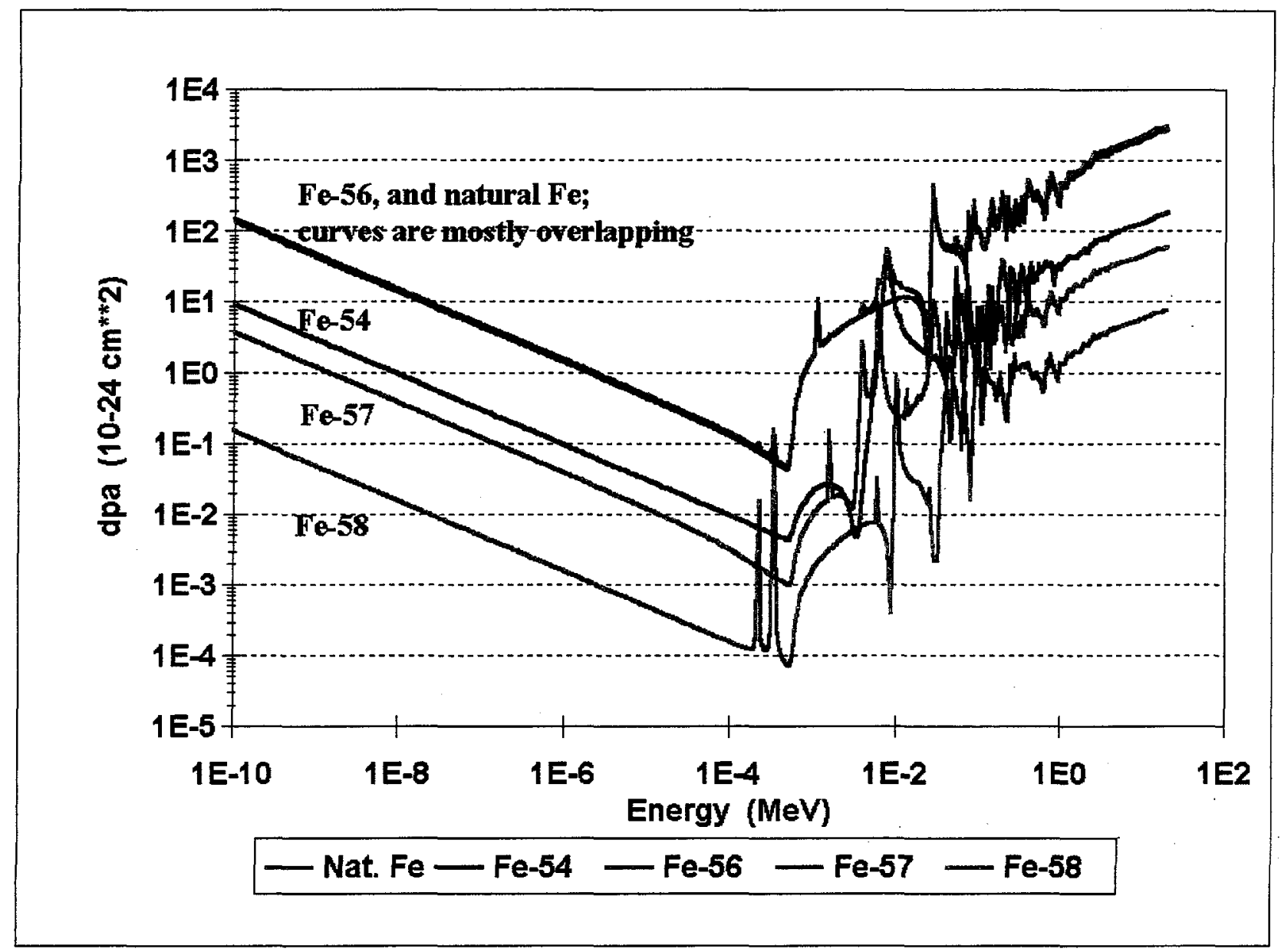

Figure 4 Contributions of the iron isotopes to the displacement cross sections of natural iron 


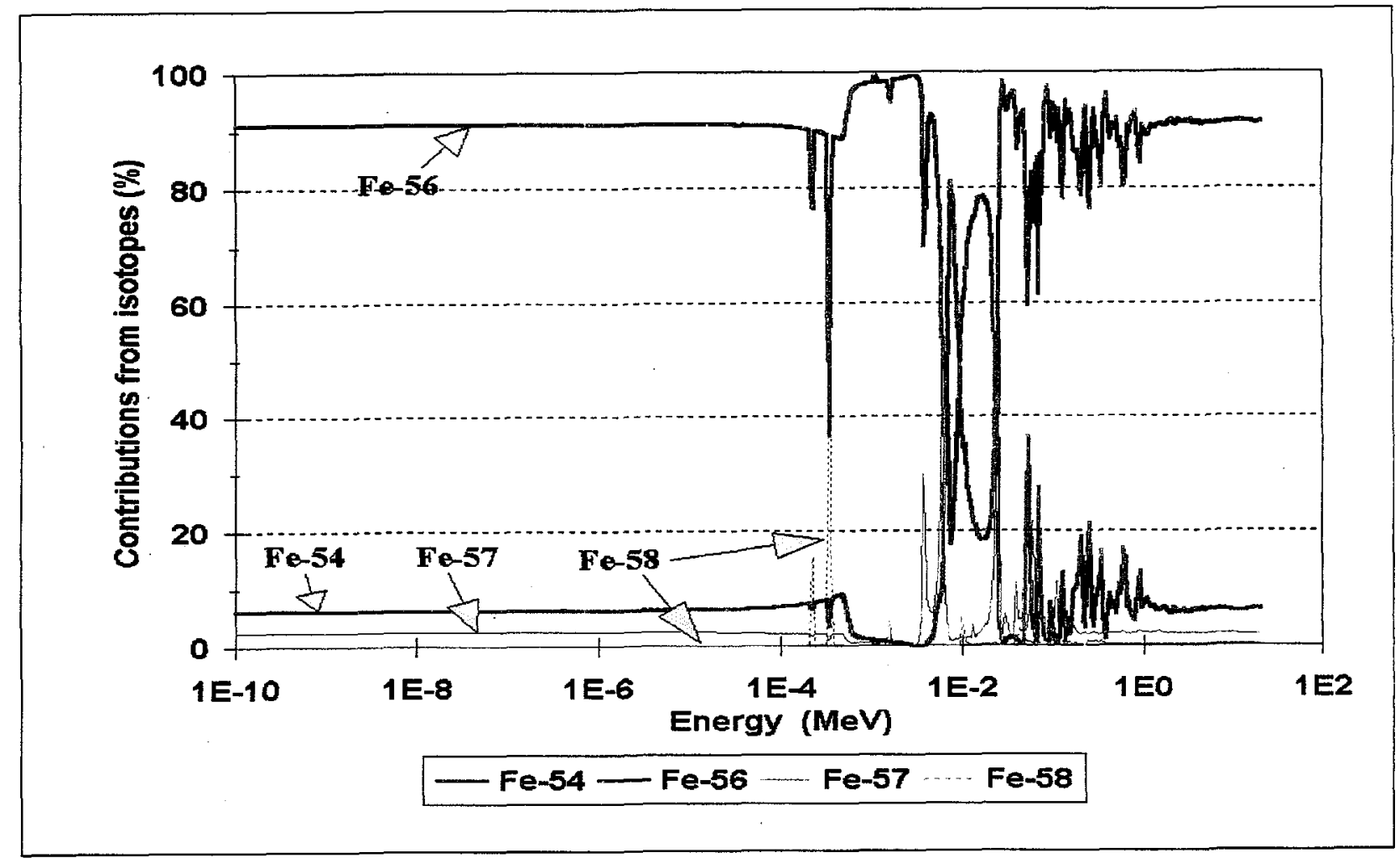

Figure 5 Relative contributions (in percent) of the individual iron isotopes to the displacement cross sections of natural iron 


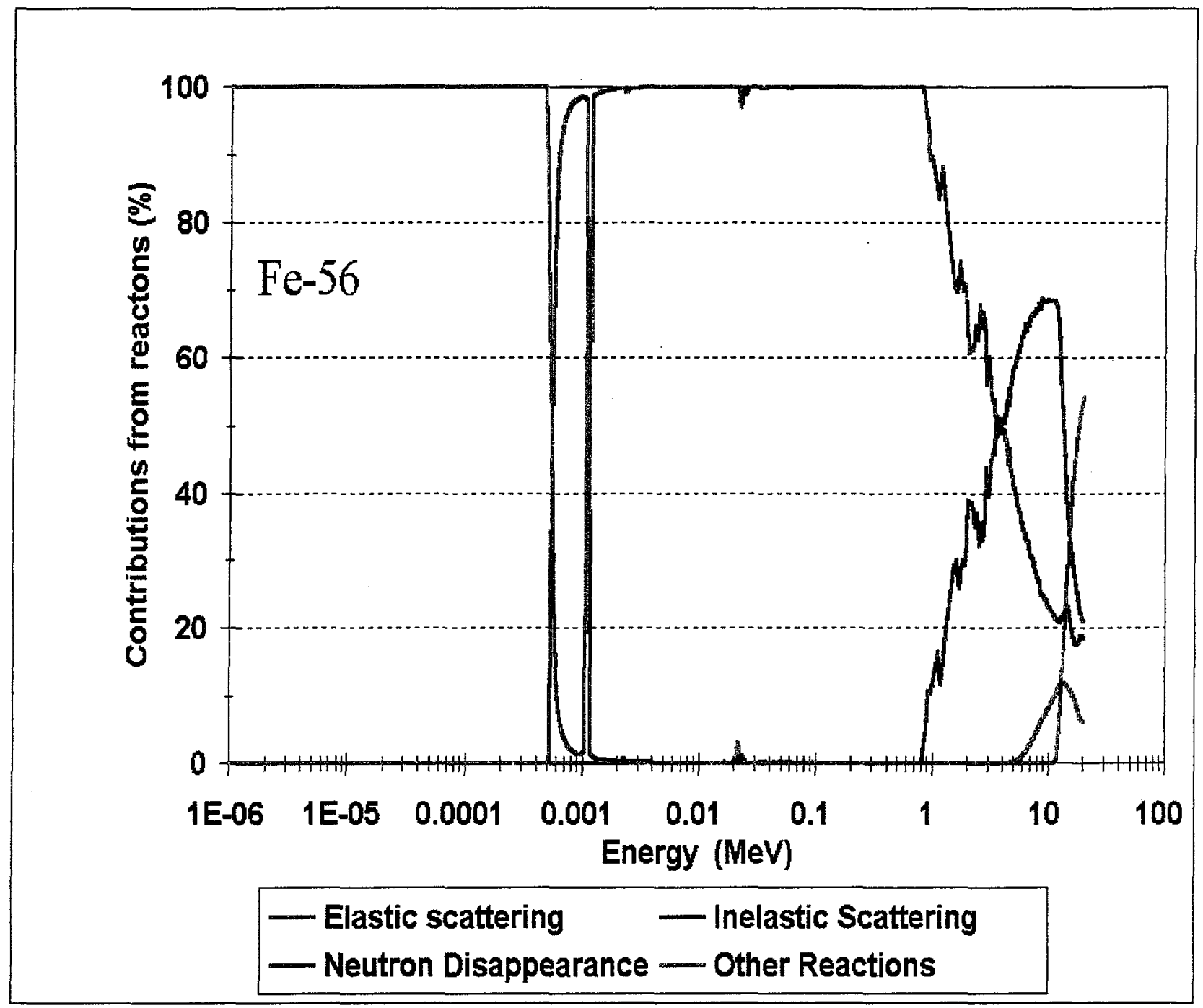

Figure 6 Relative contributions (in percent) of different types of neutron reactions to the total dpa cross sections for Fe-56 


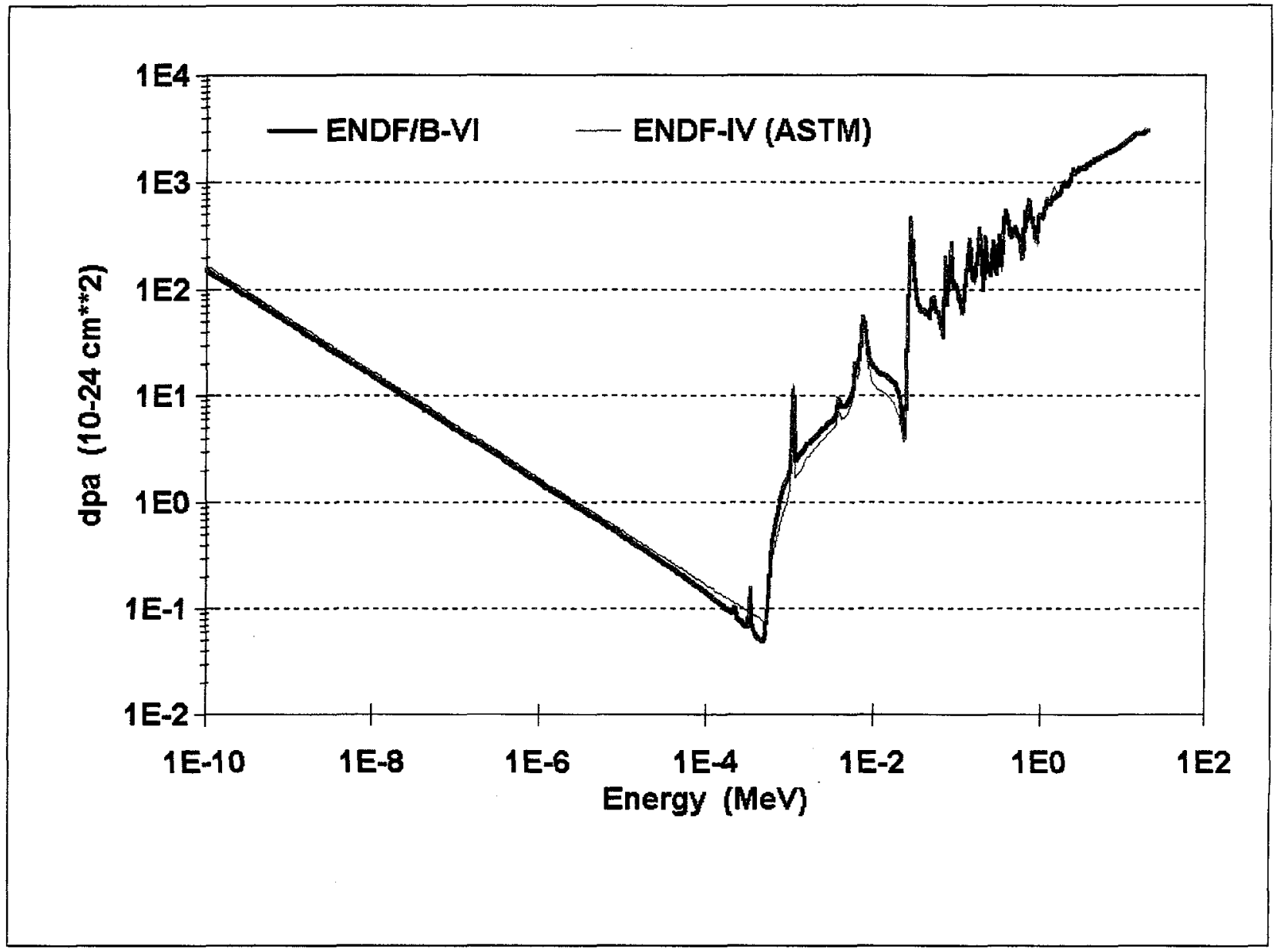

Figure 7 Comparison of the "new" ENDF/B-VI iron-displacement cross sections and the iron- displacement cross sections from ASTM standard E 693 


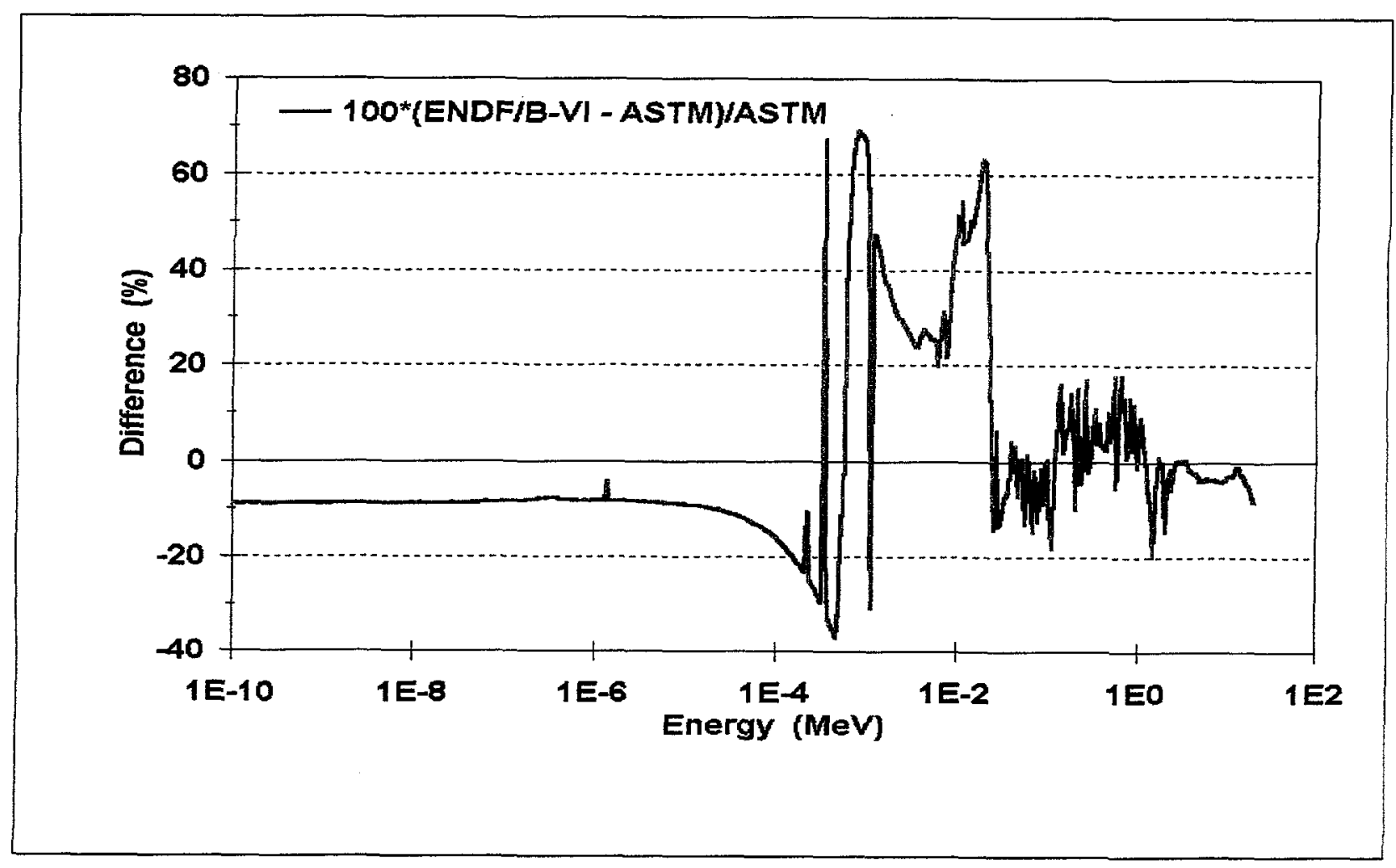

Figure 8 Differences (in percent) between the "new" (ENDF/B-VI) and "old" irondisplacement cross sections 


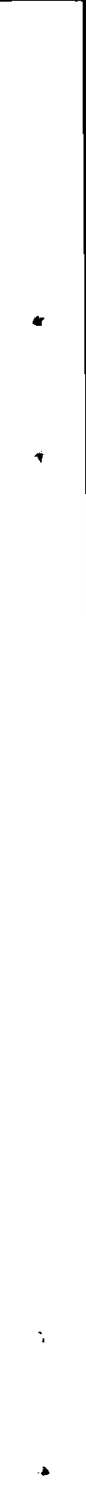




\section{INTERNAL DISTRIBUTION}

1. K. J. Clayton

2. H. T. Hunter

3. D. T. Ingersoll

4. M. A. Kuliasha

5. J. V. Pace III

6. C. E. Pugh

7. I. Remec

8. C. H. Shappert

9. D. B. Simpson
10. J. A. Wang

11. R. M. Westfall

12. J. E. White

13. B. A. Worley

14. Central Research Library

15-16. Laboratory Records for Submission to OSTI

17. Laboratory Records - RC

\section{EXTERNAL DISTRIBUTION}

18. A. Abderrahim, SCK/CEN Fuel Research Unit, Boeretang 200, B-2400 MOL, Belgium

19. J. Adams, NIST, Bldg. 235, A-156, Gaithersburg, MD 20899-0001

20. A. F. Albornoz, National Atomic Energy Comm., Advanced Reactors Phys. Div., Ar. Ezequiel Bustillo 9500, 8400 San Carlos De Bariloche, Ris Negro, Argentine

21. S. L. Anderson, Radiation and Environmental Systems, Westinghouse Electric Corporation, Nuclear Energy Systems, Monroeville Nuclear Center, P.O. Box 355, Pittsburgh, PA 15230

22. J. F. Carew, Bldg. 130, Department of Nuclear Engineering, Brookhaven National Laboratory, Upton Long Island, New York 11973

23. J. W. Craig, U.S. Nuclear Regulatory Commission, Division of Engineering Technology, MS-T10D20, Washington, DC 20555-0001

24. I. Curl, AEA Technology plc, Reactor Physics, Shielding \& Criticality Dept., Winfrith, Dorchester, Dorset, DT28DH, United Kingdom

25. P. D'Hondt, SCK/CEN, Boeretang 200, B-2400 MOL, Belgium

26. C. J. Fairbanks, U.S. Nuclear Regulatory Commission, Materials Engineering Branch, Two White Flint North, MS-T10E10, 11545 Rockville Pike, N. Bethesda, MD 20852-2783

27. P. J. Griffin, Radiation Metrology Laboratory, MS 1172, Sandia National Laboratories, P.O. Box 5800, Albuquerque, NM 87112

28. E. M. Hackett, U.S. Nuclear Regulatory Commission, Materials Engineering Branch, MST 10 E10, Washington, DC 20555

29. A. Haghighat, The Pennsylvania State University, 231 Sackett Bldg., University Park, PA $16802-1408$

30. W. R. Jones, U.S. Nuclear Regulatory Commission, Reactor Analysis Branch, MS-T 4 A9, Washington, DC 20555

31. E. P. Lippincott, 1776 McClure Rd., Monroeville, PA 15146 
32. L. Lois, Office of Nuclear Regulatory Research, Division of Systems Safety and Analysis, MS-ONFN8E23, Washington, DC 20555-0001

33. M. E. Mayfield, U.S. Nuclear Regulatory Commission, Materials Engineering Branch, MS-T10E10, N. Bethesda, MD 20852-2783

34. M. A. Mitchell, U.S. Nuclear Regulatory Commission, Materials and Chemical Engineering Branch, MS-O 7 D4, Washington, DC 20555

35. B. C. Na, OECD Nuclear Energy Agency, Le Seine St-Germain, 12 boul.des Iles, 92130 Issy les Moulineaux, France

36. E. Polke, Siemens-KWU, Freyeslebenstr.1, D-91058 Erlangen, Germany

37. G. Reffo, Italian National Agency for New Technology, C.R.E. e. CLEMENTEL, Via Martiri di Monte Sole n.4, 40129 - Bologna Italy

38. M. Suzuki, Reactor Component Reliability, Dept. Of Reactor Safety Res., JAERI, Tokaimura, Ibaraki 319-11

39. R. D. Thompson, U.S. Nuclear Regulatory Commission, Property and Oversight Branch, Mail Stop T-7 I2, Washington, DC 20555-0001

40. W. T. Urban, Los Alamos National Laboratory, MS B 226 Los Alamos, New Mexico

41. J. G. Williams, University of Arizona, Nuclear Reactor Laboratory, Dept. of Nuclear \& Energy Engineering, Tucson, AZ 85721

42. M. L. Williams, LSU Nuclear Science Center, Louisiana State University, Baton Rouge, LA 70803

43. S. Zaritsky, Kurchatov Institute, Kurchatov Square, 123182 Moscow, Russia 